\title{
The Characteristic Long-Term Upregulation of Hippocampal NF- $\kappa$ B Complex in PTSD-Like Behavioral Stress Response Is Normalized by High-Dose Corticosterone and Pyrrolidine Dithiocarbamate Administered Immediately after Exposure
}

\author{
Hagit Cohen*,', Nitsan Kozlovsky', Michael A Matar', Joseph Zohar' and Zeev Kaplan' \\ 'The State of Israel Ministry of Health, Anxiety and Stress Research Unit, Faculty of Health Sciences, Ben-Gurion University of the Negev, \\ Beer-Sheva, Israel; 'Division of Psychiatry, The State of Israel Ministry of Health, The Chaim Sheba Medical Center, Sackler Medical School, \\ Tel-Aviv University, Ramat-Gan, Israel
}

Nuclear factor- $\kappa \mathrm{B}(\mathrm{NF}-\kappa \mathrm{B})$ is a ubiquitously expressed transcription factor for genes involved in cell survival, differentiation, inflammation, and growth. This study examined the role of NF- $\kappa$ B pathway in stress-induced PTSD-like behavioral response patterns in rats. Immunohistochemical technique was used to detect the expression of the NF- $\kappa$ B p50 and p 65 subunits, I- $\kappa \mathrm{B} \alpha$, p38, and phospho-p38 in the hippocampal subregions at 7 days after exposure to predator scent stress. Expression of p65 nuclear translocation was quantified by western blot as the level of NF- $\kappa$ B activation. The effects of intraperitoneally administered corticosterone or a selective NF- $\kappa$ B inhibitor (pyrrolidine dithiocarbamate (PDTC)) at I h post exposure on behavioral tests (elevated plus-maze and acoustic startle response) were evaluated 7 days later. Hippocampal expressions of those genes were subsequently evaluated. All data were analyzed in relation to individual behavior patterns. Extreme behavioral responder animals displayed significant upregulation of p50 and p65 with concomitant downregulation of $1-\kappa \mathrm{B} \alpha, \mathrm{p} 38$, and phospho-p38 levels in hippocampal structures compared with minimal behavioral responders and controls. Immediate post-exposure treatment with high-dose corticosterone and PDTC significantly reduced prevalence rates of extreme responders and normalized the expression of those genes. Stress-induced upregulation of NF- $\kappa$ B complex in the hippocampus may contribute to the imbalance between what are normally precisely orchestrated and highly coordinated physiological and behavioral processes, thus associating it with stress-related disorders.

Neuropsychopharmacology (20II) 36, 2286-2302; doi:10.1038/npp.20II.II8; published online 6 July 20II

Keywords: animal model; post-traumatic stress disorder; nuclear factor- $\kappa \mathrm{B}$ (NF- $\kappa \mathrm{B})$; corticosterone; pyrrolidine dithiocarbamate; p38 receptor

\section{INTRODUCTION}

The nuclear factor- $\kappa \mathrm{B}$ (NF- $\kappa \mathrm{B}$ ), or Rel, family of eukaryotic transcription factors (TFs) positively regulates a broad range of genes and plays a pivotal role in immune and inflammatory responses, neuronal plasticity, memory formation, and cell death and survival (Chen et al, 1999; Freudenthal et al, 2005; Kaltschmidt et al, 2005; Li et al, 2008; Li and Verma, 2002; Mattson, 2005; Mattson and Meffert, 2006; Meffert and Baltimore, 2005; O'Mahony et al, 2006; Yeh et al, 2002). The NF- $\kappa \mathrm{B}$ family consists of five members: p50, p52, p65, c-Rel, and RelB (Meffert and

* Correspondence: Professor H Cohen, Anxiety and Stress Research Unit, Ministry of Health Mental Health Center, Faculty of Health Sciences, Ben-Gurion University of the Negev, P.O. Box 4600, Beer-Sheva 84170 Israel, Tel: +9728640 1743, Fax: +9728640 1742, E-mail: hagitc@bgu.ac.il

Received I February 20 I I; revised 2 June 20 I I; accepted 2 June 20 I I
Baltimore, 2005). All family members share a Rel homology domain, which contains the crucial functional regions for DNA binding, dimerization, and nuclear localization, and for interaction with the inhibitory I- $\kappa \mathrm{B}$ proteins (Baeuerle and Baltimore, 1988), which inhibit NF- $\kappa$ B activity when it is not required. In the CNS, the most widely NF- $\kappa$ B subunits are p50 and p65 (Denk et al, 2000).

Under basal conditions, heterodimers of NF- $\kappa \mathrm{B}$, typically p50 and p65, are sequestered in the cytosol, where they are constitutively bound by members of the NF- $\kappa \mathrm{B}$ inhibitor family of proteins, mainly I- $\kappa \mathrm{B}$ (I- $\kappa \mathrm{B} \alpha$ and I- $\kappa \mathrm{B} \beta$ ) (Schmitz et al, 2001; Yu et al, 1999). Upon stimulation, I- $\kappa \mathrm{B}$ is phosphorylated by the I- $\kappa \mathrm{B}$ kinase complex I $\kappa \kappa$, ubiquitinated, and consequently degraded by the $26 \mathrm{~S}$ proteasome (Ben-Neriah, 2002). The released NF- $\kappa$ B then translocates to the nucleus, binds to its cognate DNA element, and activates the transcription of numerous target genes (Baeuerle and Baltimore, 1996; Clemens et al, 1997). A variety of factors can stimulate the activation of NF- $\kappa \mathrm{B}$, including proin- 
flammatory cytokines such as tumor necrosis factor- $\alpha$ and interleukin-1, physical or oxidative stress, bacterial or viral proteins, nerve growth factor, lipopolysaccharides, and reactive oxygen species (Barger et al, 1995; Kaltschmidt et al, 1995; Maggirwar et al, 1998; Schreck and Baeuerle, 1994; Webster et al, 2002; Yu et al, 1999). Depending on the activating stimulus, NF- $\kappa \mathrm{B}$ may be subject to posttranslational modifications that can enhance transcriptional activation of NF- $\kappa \mathrm{B}$-dependent genes (De Bosscher and Haegeman, 2009). Besides the classical NF- $\kappa$ B activation pathway, additional regulatory mechanisms have been identified that fine-tune nuclear NF- $\kappa \mathrm{B}$ responses in a gene-specific way (Beck et al, 2008).

The role of $\mathrm{NF}-\kappa \mathrm{B}$ in the brain is presently unclear; because the activation of $\mathrm{NF}-\kappa \mathrm{B}$ is associated with cell injury and death in many different pathological settings (eg, ischemia and Parkinson), it has been proposed that the activation of NF- $\kappa \mathrm{B}$ contributes to excitotoxic damage and to the cell death process (Clemens et al, 1997; Grilli et al, 1996; Yu et al, 1999). On the other hand, the activation of $\mathrm{NF}-\kappa \mathrm{B}$ has been reported to promote neuronal survival in various models (Barger et al, 1995; Bhakar et al, 2002; Guo et al, 1998; Mattson et al, 1997; Taglialatela et al, 1997; Yu et al, 1999), and a compete blockade of neuronal NF- $\kappa \mathrm{B}$ activity resulted in a loss of neuroprotection in kainitetreated hippocampal slices (Fridmacher et al, 2003).

Evidence from pharmacological and genetic studies of the $\mathrm{NF}-\kappa \mathrm{B}$ complex in relation to anxiety-related behaviors and stress suggests that the NF- $\kappa \mathrm{B}$ complex is indeed involved in emotional behavior and stress response (Koo et al, 2010; Kubera et al, 2011). For instance, Kassed and Herkenham (2004) reported that mice with a null mutation of the p50 subunit exhibited a distinctive behavioral phenotype characterized by decreased anxiety-like responses, elevated exploratory behavior, and reduced tendency to establish dominant-subordinate relationships among their cage mates. Koo et al (2010) reported that depressive-like behaviors caused by exposure to chronic stress are mediated by NF- $\kappa \mathrm{B}$ signaling. It was recently reported that acute stress increases the DNA-binding activity of NF- $\kappa \mathrm{B}$ in peripheral blood mononuclear cells (Bierhaus et al, 2003; Richlin et al, 2004; Vider et al, 2001). Moreover, male major depression patients with increased early life stress exhibit enhanced NF- $\kappa \mathrm{B}$ to psychosocial stress, providing a preliminary indication of a link between major depression, early life stress, and adverse health outcomes in diseases associated with inflammation (Pace et al, 2006).

The NF- $\kappa \mathrm{B}$ complex has been reported to be involved in a confounding array of processes, including cell growth and cell death, and it appears to be important in many stressrelated processes. This study examined the relationship between the expression of the NF- $\kappa \mathrm{B}$ complex response to stress in the hippocampal subareas and patterns of behavioral response. This study design involved the inescapable exposure of rodents to predator-scent stress (PSS) and behavioral testing on the elevated plus-maze (EPM) and acoustic startle response (ASR) tests. Biomolecular and physiological parameters were studied shortly after behavioral testing was completed. The key factor of the method was the approach to data analysis, entitled the cutoff behavioral criteria (CBC) method. In this approach, the behaviors of individual animals within each study group on both the EPM and ASR are used as a tool to classify individuals into groups corresponding to extreme behavioral response (EBR), minimal behavioral response (MBR), and partial behavioral response (PBR). Behavioral classification enables the assessment of physiological and biomolecular parameters in relation to the magnitude or severity of stress-induced behavioral disruption based on prevalence rates of each of the above within each study group, that is, under the various study conditions.

We examined the relationship between stress-induced PTSD-like behavioral response patterns in rats and levels of the NF- $\kappa \mathrm{B}$ subunits $\mathrm{p} 50$ and p $65, \mathrm{I}-\kappa \mathrm{B} \alpha, \mathrm{p} 38$, and phosphop38 in the hippocampus subareas. Two distinct NF- $\kappa \mathrm{B}$ inhibitors, pyrrolidine dithiocarbamate salt (PDTC) and corticosterone $(25 \mathrm{mg} / \mathrm{kg})$ were administrated $1 \mathrm{~h}$ post-PSS exposure to block NF- $\kappa \mathrm{B}$ activation. PDTC is a highly interesting compound with a dual mechanism of action as an antioxidant and a specific inhibitor of the NF- $\kappa \mathrm{B}$ (Nurmi et al, 2006; Soerensen et al, 2009). PDTC reversibly inhibits the nuclear translocation of $\mathrm{NF}-\kappa \mathrm{B}$ by decreasing the concentration of metal ions and hydroxyl radicals that are required for the release of $\mathrm{I} \kappa \mathrm{B}$ from NF- $\kappa \mathrm{B}$ (Hayakawa et al, 2003; Liu et al, 1999; Schreck et al, 1992; Ziegler-Heitbrock et al, 1993). Glucocorticoids (GCs) are among the most used anti-inflammatory and immunosuppressive drugs. GCs induce $\mathrm{I} \kappa \mathrm{B} \alpha$ expression, preventing nuclear translocation of NF- $\kappa \mathrm{B}$ (Aljada et al, 1999; Munhoz et al, 2006; Quan et al, 2000 ), and/or interact with the NF- $\kappa \mathrm{B}$ p65 subunit, thereby blocking NF- $\kappa \mathrm{B}$-binding activity (Aljada et al, 1999; De Bosscher et al, 2000; Munhoz et al, 2006; Quan et al, 2000; Unlap and Jope, 1997). The associations between behavioral responses and NF- $\kappa \mathrm{B}$ subunits and p38/phospho-p38 expression were also evaluated.

\section{MATERIALS AND METHODS}

\section{Animals}

Adult male Sprague-Dawley rats weighing 175-225 g were habituated to housing conditions for at least 7 days, and they were housed four per cage in a vivarium with stable temperature and a reversed 12-h light/dark cycle (lights off at $0800 \mathrm{~h}$ ) where they had unlimited access to food and water. Animals were handled once daily.

\section{Experimental Design}

Three experiments were conducted. In the first, the expression of protein levels for the p50 and p65 submits of the NF- $\kappa \mathrm{B}$ complex, I- $\kappa \mathrm{B} \alpha, \mathrm{p} 38$, and phospho-p38 were evaluated in selected areas of harvested brains from animals classified according to CBC at day 7 post-PSS exposure. Expression of p65 nuclear translocation as the level of NF$\kappa \mathrm{B}$ activation was quantified using western blot. In the second, animals were exposed to PSS, treated with a high dose $(25 \mathrm{mg} / \mathrm{kg})$ of corticosterone and assessed behaviorally in the EPM and ASR tests at day 7. Local levels of p50, p65, $\mathrm{I}-\kappa \mathrm{B} \alpha, \mathrm{p} 38$, and phospho-p38 in selected brain areas were then evaluated. The last experiment assessed the effects of a PDTC administration $1 \mathrm{~h}$ after PSS on behavioral responses and hippocampal expression of $\mathrm{p} 50, \mathrm{p} 65, \mathrm{I}-\kappa \mathrm{B} \alpha, \mathrm{p} 38$, and phospho-p38. 


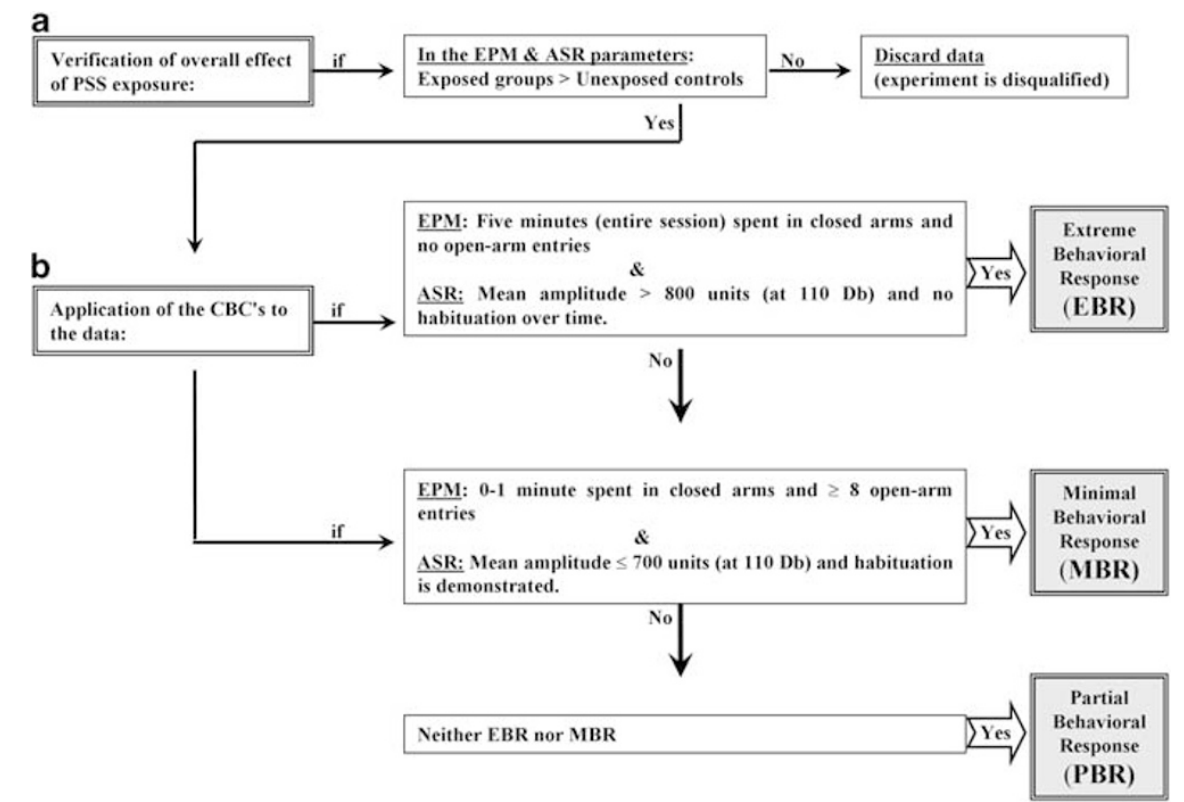

Figure I The cutoff behavioral criteria (CBC) algorithm. In order to approximate the approach to understanding animal behavioral models more closely to contemporary clinical conceptions of PTSD, we use an approach that enables the classification of study animals into groups according to degree of response to the stressor, that is, the degree to which individual behavior is altered or disrupted. In order to achieve this, behavioral criteria were defined and then complemented by the definition of cutoff criteria reflecting severity of response; this parallels inclusion and exclusion criteria applied in clinical research. The procedure requires the following steps: (a) Verification of global effect: The data must demonstrate that the stressor had a significant effect on the overall behavior of exposed vs unexposed populations at the time of assessment. (b) Application of the CBCs to the data: In order to maximize the resolution and minimize false positives, extreme responses to both elevated plus-maze (EPM) and acoustic startle response (ASR) paradigms, performed in sequence, were required for 'inclusion' into the EBR group, whereas a negligible degree of response to both was required for inclusion in the MBR group.

\section{Predator Scent Stress}

Test animals were placed on well-soiled cat litter (in use by the cat for 2 days, sifted for stools) in a plastic cage (inescapable exposure) placed on the paving of a yard, for $10 \mathrm{~min}$ in a closed environment. Control animals were exposed to fresh, unused litter for the same amount of time.

\section{Behavioral Measurements}

Behavioral responses were assessed in the EPM and the ASR paradigm based on previous data (Cohen et al, 2003, 2004, 2006, 2008b).

\section{The CBC Model}

The classification of individuals according to the degree to which their individual behavior was affected by a stressor is based on the premise that extremely compromised behavior in response to the priming trigger is not conducive to survival and is thus inadequate and maladaptive, representing a pathological degree of response (Cohen et al, 2003, 2004, 2005; Cohen and Zohar, 2004). The procedure is detailed in Figure 1.

\section{Tissue Preparation}

At $24 \mathrm{~h}$ after the behavioral tests, animals were deeply anesthetized (ketamine and xylazine mixture) and perfused transcardially with cold $0.9 \%$ physiological saline followed by $4 \%$ paraformaldehyde (Sigma-Aldrich) in $0.1 \mathrm{M}$ phos- phate buffer ( $\mathrm{pH}$ 7.4). Brains were quickly removed, postfixed in the same fixative for $12 \mathrm{~h}$ at $4{ }^{\circ} \mathrm{C}$, and were cryoprotected overnight in $30 \%$ sucrose in $0.1 \mathrm{M}$ phosphate buffer at $4{ }^{\circ} \mathrm{C}$. Brains were frozen on dry ice and stored at $-80{ }^{\circ} \mathrm{C}$. Serial coronal sections $(10 \mu \mathrm{m})$ at the level of dorsal hippocampus were collected from each animal, using a cryostat (Leica CM 1850) and mounted on coated slides.

\section{Immunohistochemical}

Sliced sections were air dried and incubated in frozen methanol ( $2 \mathrm{~min}$ ) and in $4 \%$ paraformaldehyde (4 min). After three washes in phosphate-buffer saline (PBS) containing Tween 20 (PBS/T) (Sigma-Aldrich), the sections were incubated for $60 \mathrm{~min}$ in a blocking solution in (normal goat or horse serum in PBS) and then overnight at $4{ }^{\circ} \mathrm{C}$ with the primary antibodies against $\mathrm{p} 50, \mathrm{p} 65, \mathrm{I}-\kappa \mathrm{B} \alpha, \mathrm{p} 38$, and phospho-p38 (1:250 each; Santa Cruz Biotechnology, Santa Cruz, CA). After three washes in PBS/T, sections were incubated in DyLight-488 labeled goat-anti-rabbit IgG or Dylight-594 goat anti-mouse IgG (1:250; KPL, Gaithersburg, MD) in PBS containing $2 \%$ normal goat or house serum for $2 \mathrm{~h}$. Sections were washed, mounted with mounting medium (Vectrastain Vector Laboratories, Burlingame, CA). Control staining was performed in the absence of the primary antibodies. Additionally, secondary fluorescent labels were swapped to check crossreactivity and sections were incubated without any primary antibodies to check for any nonspecific binding of the secondary antibodies. 

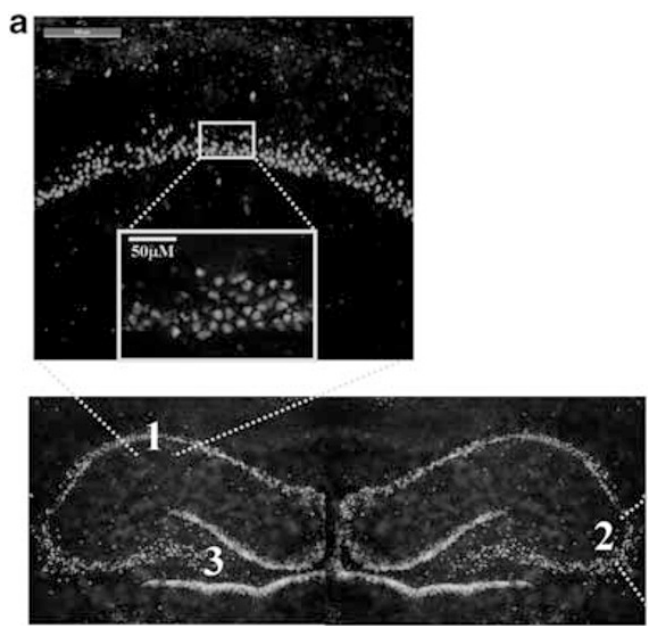

b
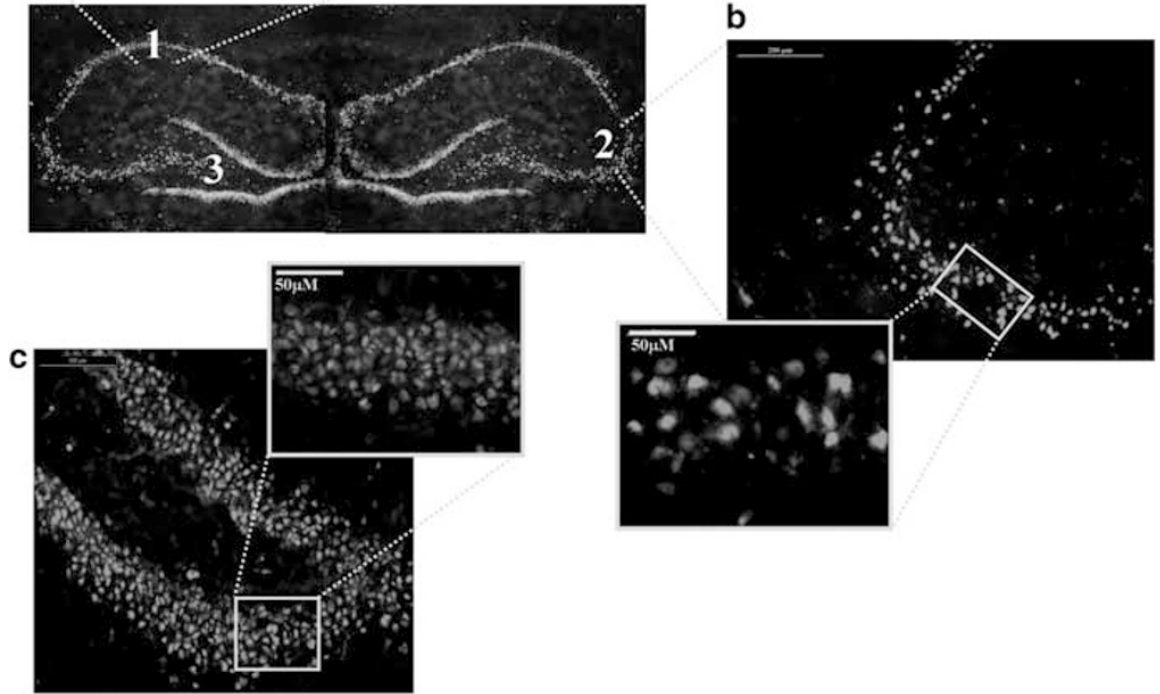

Figure 2 Representative photomicrographs showing regions of interest for the immunohistochemical staining analysis: (a) hippocampal subregions of ammons horn (cornu ammonis) I (CAI), (b) CA3, and (c) DG. Coronary sections, light microscope $(\times 10)$. The locations of the section regions used to analyze are shown by white rectangles, light microscope $(\times 50)$.

\section{Quantification}

A computer-assisted image analysis system (Leica Application Suite V3.6, Leica, Germany) was used for quantitative analysis of the immunostaining and $\times 50$ objective lens were employed to assess the number of cells positive for p50-IR, p65-IR, I- $\kappa B \alpha-I R, p 38-I R$, and phospho-p38-IR in the hippocampus, divided into three (counted separately) areas: CA1 subfield, CA3 subfield, and DG. The regions of interest were outlined and computer-aided estimation was used to calculate the number of p50-IR, p65-IR, I- $\kappa \mathrm{B} \alpha$-IR, p38-IR, and phospho-p38-IR cells in the pyramidal layer of CA1 and CA3, and in the granular layer of DG (Figure 2). Six representative sections of the hippocampus were chosen (between Bregma -2.30 and Bregma -3.60) from each animal, from each group (Paxinos and Watson, 2005). The sections were analyzed by two observers blinded to the treatment protocol. Standard technique was used to estimate the number of p50-IR, p65-IR, I- $\kappa \mathrm{B} \alpha$-IR, p38-IR, and phospho-p38-IR cell profiles per unit area for each investigated hippocampal structure.

\section{Western Blotting}

Brains were immediately removed from the decapitated rats. The DG, CA1, and CA3 subregions of the hippocampus from each rat were dissected and frozen at $-70^{\circ} \mathrm{C}$ for analysis.

\section{Cytosolic and Nuclear Extracts}

Brain samples extracted from the hippocampal CA1, CA3, and DG were homogenized in $300 \mu \mathrm{l}$ lysis buffer by 20 strokes in a Dounce homogenizer (Pastele A) at $4{ }^{\circ} \mathrm{C}$. Homogenates were centrifuged for $10 \mathrm{~min}$ at low speed $\left(2500 \mathrm{~g}\right.$ at $\left.4{ }^{\circ} \mathrm{C}\right)$. The resulting supernatant and pellet were further processed to generate cytosol and nuclear extract, respectively. For cytosol preparation, supernatant was centrifuged $\left(40000 \mathrm{~g}\right.$ at $\left.4{ }^{\circ} \mathrm{C}\right)$ for $30 \mathrm{~min}$. The final supernatant was used as the cytosolic tissue fraction. For nuclear extract preparation, the pellet from low-speed centrifugation of homogenate was washed twice by resuspension in $0.5 \mathrm{ml}$ of homogenization buffer, followed by additional low-speed centrifugation $\left(5 \mathrm{~min}, 2000 \mathrm{~g}\right.$ at $4{ }^{\circ} \mathrm{C}$ ). The washed pellet was then resuspended in $100 \mu$ of homogenization buffer and sonicated for $15 \mathrm{~s}, 4^{\circ} \mathrm{C}$ at $50 \%$ power capacity (Sonics and Materials, Newtown, CT). After centrifugation $\left(14000 \mathrm{~g}, 4^{\circ} \mathrm{C}\right.$, $20 \mathrm{~min}$ ), the supernatant was removed to a fresh tube and was kept as the nuclear fraction. Protein concentrations for each cytosolic and nuclear sample were determined according to the Bradford method.

\section{Western Blotting}

Western blot assays were performed according to a method modified from the procedure of Spencer et al (2000). For electrophoretic analysis, $2 \mu \mathrm{g}$ of protein from the different 
samples was boiled for $5 \mathrm{~min}$ in loading buffer and incubated for $5 \mathrm{~min}$ at $4{ }^{\circ} \mathrm{C}$. Samples were separated on $10 \%$ SDS-PAGE at $180 \mathrm{~V}$ for $40 \mathrm{~min}$, electroblotted for $2 \mathrm{~h}$ (200 mA) on PVDF membrane and blocked with TBS/T containing 5\% non-fat dry milk (Spartan, Grand Rapids, MI). For immunodetection, PVDF membranes were incubated overnight at $4{ }^{\circ} \mathrm{C}$ with a specific antibody against p65 (1:400, Santa Cruz Biotechnology), washed three times with TBS/T, and incubated for $1 \mathrm{~h}$ with the secondary antibody $(1: 2000$ goat anti-rabbit IgG-HRP, Santa Cruz Biotechnology). The immunoreactive p65 bands were detected with enhanced chemiluminescence ECL Plus kit (Amersham Bioscience, Piscataway, NJ) and exposed to a sensitive film (Kodak). Quantification of the immunoblots was performed by El Logic 100 imaging system (Kodak) and molecular imaging software (Kodak). Exposure times were adjusted so that the darkest bands did not saturate the film. Quantitated values for p65 gene expression were converted into percent values of total protein (cytosolic and nuclear extracts protein levels). To minimize the effect of interblot variability, groups were counterbalanced across gels and a single batch of protein of rat brain in two different concentrations was used for normalization in each gel.

\section{Injections}

Rats were injected intraperitoneally (i.p.) with saline $(\mathrm{NaCl}$ : $0.9 \%), 25.0 \mathrm{mg} / \mathrm{kg}$ of corticosterone (Sigma), or $150 \mathrm{mg} / \mathrm{kg}$ of PDTC (Sigma-Aldrich Israel) at $1 \mathrm{~h}$ after stress exposure or sham exposure. Control groups were given $0.9 \%$ saline solution. The corticosterone dose was determined according to our previous study (Cohen et al, 2008a) and the PDTC dose according to Soerensen et al (2009).

\section{Statistical Analyses}

Molecular data were analyzed using one-way analysis of variance (ANOVA). Behavioral data were analyzed using two-way ANOVA and the post hoc Bonferroni test for multiple comparisons. The prevalence of affected rats as a function of rat group was tested using cross-tabulation and nonparametric $\chi^{2}$ tests.

\section{RESULTS}

Control sections incubated without the primary antibody were generated and demonstrated no staining.

\section{NF- $\kappa$ B p50 and p65 Expression at Day 7 Post-PSS Exposure}

In the hippocampal subregion DG (Figure 3c), there were significant differences in p50-IR cells between groups $(\mathrm{F}(3,23)=4.2, p<0.02)$. Post hoc Bonferroni test revealed that PSS significantly increased the expression of p50 in EBR animals compared with controls $(p<0.003)$ and MBR animals $(p<0.05)$. PSS significantly increased DG $p 50$ expression in PBR animals compared with controls $(p<0.03)$. In the CA1 and CA3 subregions (Figure $3 a$ and b), no significant differences were found between exposed animals and controls.
In the CA1 (Figure 4a) and DG (Figure 4c) subregions, there were significant differences in p65-IR cells between groups $(\mathrm{F}(3,32)=4.25, p<0.02$ and $\mathrm{F}(3,32)=8.8, p<0.0006$, respectively). Bonferroni test revealed that PSS significantly increased p65 expression in EBR, PBR, and MBR animals compared with controls $(p<0.05, p<0.025$, and $p<0.01$, respectively). In the DG subregion, PSS exposure significantly increased p65 expression in EBR rats compared with PBR $(p<0.05)$, MBR $(p<0.03)$, and naive controls $(p<0.045)$. In the CA3 subregion (Figure $4 \mathrm{~b})$, no significant differences were found between the groups.

\section{NF- $\kappa$ B p65 Translocation to the Nucleus 7 Days Post-PSS Exposure}

In the DG subregion, two-way ANOVA revealed a significant effect for groups $(\mathrm{F}(3,28)=8.1, p<0.0005)$ and a significant effect for cellular fraction $(F(1,28)=17.6$, $p<0.0003$; Figure $5 \mathrm{a}-\mathrm{c})$. In the cytosolic fraction, $\mathrm{p} 65$ protein levels were not significantly different between groups. In the nuclear fraction, p65 protein levels at 1 week post-stress exposure were higher in the EBR individuals compared with controls $(p<0.015)$ and MBR individuals $(p<0.05)$. Nuclear $p 65$ protein levels were significantly lower in the EBR and MBR individuals compared with their cytosolic fractions ( $p<0.015$ and $p<0.002$, respectively).

\section{I- $\kappa \mathrm{B} \alpha$ Expression at Day 7 Post-PSS Exposure}

In the CA3 (Figure 6b) and DG (Figure 6c) subregions, there were significant differences between groups $(\mathrm{F}(3,32)=3.9$, $p<0.02$ and $\mathrm{F}(3,32)=3.4, p<0.03$, respectively). Bonferroni test revealed that PSS significantly increased CA3 I- $\kappa \mathrm{B} \alpha$ expression in $\mathrm{MBR}$ animals compared with control, $\mathrm{EBR}$, and PBR animals $(p<0.05, p<0.002$, and $p<0.045$, respectively). In the DG subregion (Figure 6c), PSS exposure significantly increased I- $\kappa \mathrm{B} \alpha$ expression in MBR rats compared with EBR and PBR animals $(p<0.015$ and $p<0.008$, respectively). In the CA1 subregion, no significant differences were found between the groups.

\section{P38/phospho-p38 Expression at Day 7 Post-PSS Exposure}

In the CA1 (Figure 7a), CA3 (Figure 7b), and DG (Figure 7c) subregions, there were significant differences in p38-IR cells between groups $(\mathrm{F}(3,28)=6.8, p<0.0015 ; \mathrm{F}(3,28)=7.8$, $p<0.0007$; and $\mathrm{F}(3,28)=12.5, p<0.0001$, respectively). Post hoc Bonferroni test revealed that PSS significantly decreased CA1 p38 expression in all exposed groups compared with controls (Bonferroni test: $p<0.0001, p<0.02$, and $p<0.015$ ). In CA3, PSS significantly decreased p38 expression in EBR animals compared with controls, PBR, and MBR animals $(p<0.0003, p<0.002$, and $p<0.0004$, respectively). In DG, PSS significantly decreased p38 expression in EBR and PBR animals compared with controls ( $p<0.0001$ for both) and MBR animals ( $p<0.0001$ and $p<0.0002$, respectively).

In the CA1 (Figure 7d), CA3 (Figure 7e), and DG (Figure 7f) subregions, there were significant differences in phospho-p38-IR cells between groups $(\mathrm{F}(3,28)=9.7$, $p<0.0002 ; \quad \mathrm{F}(3,28)=4.0, \quad p<0.02 ; \quad$ and $\mathrm{F}(3,28)=19.4$, $p<0.0001$, respectively). Bonferroni test revealed that PSS significantly decreased CA1, CA3, and DG phospho-p38 
a
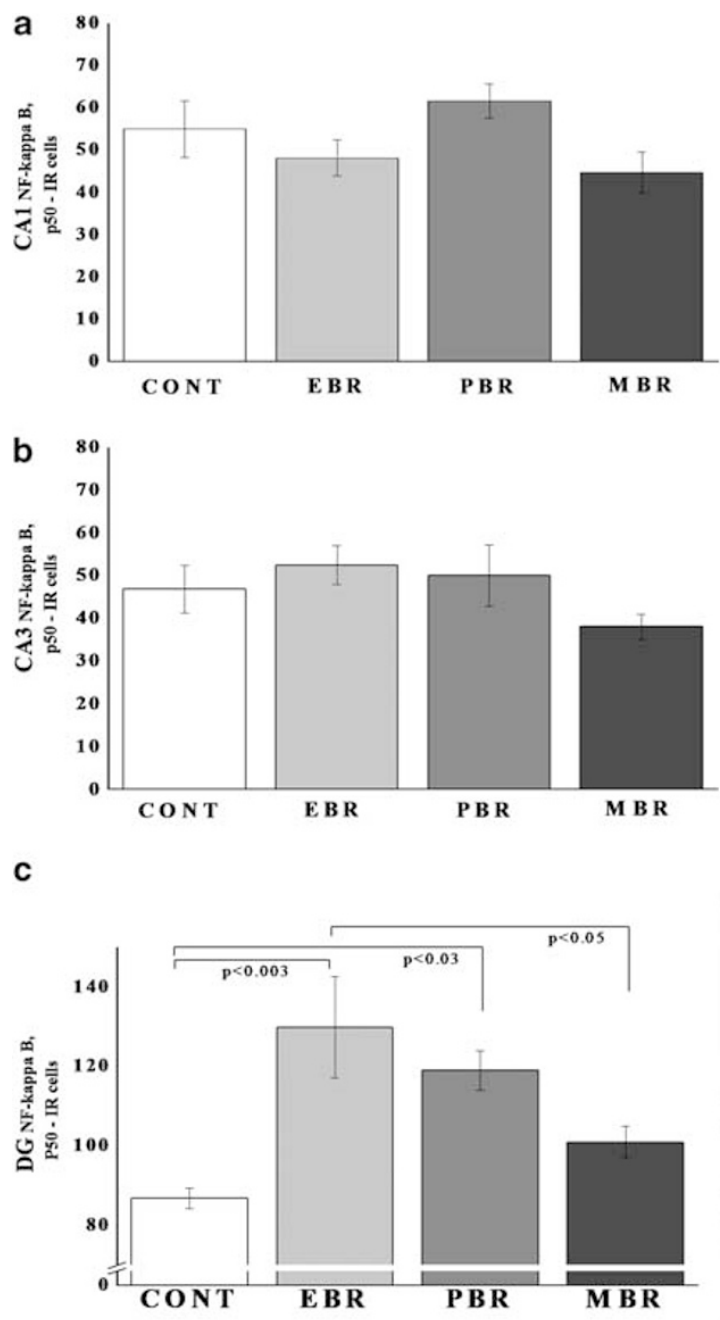

CONT
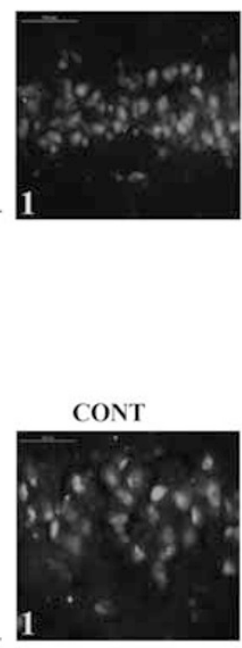

CONT
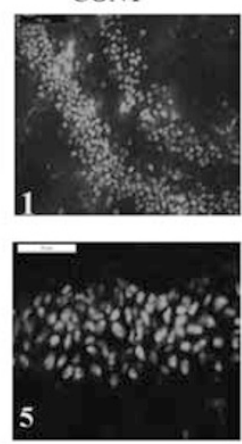

EBR

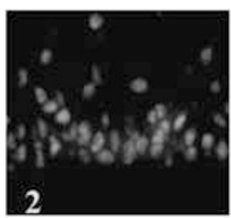

PBR

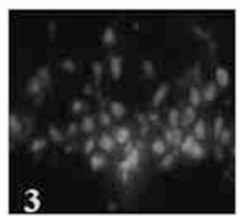

MBR

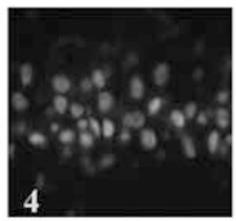

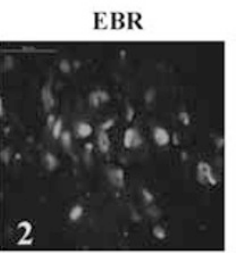
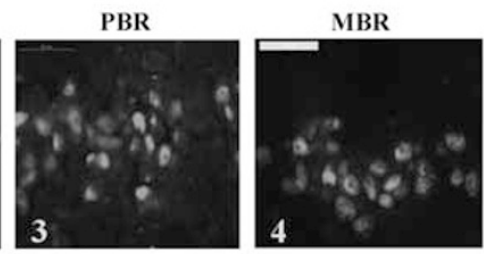

EBR

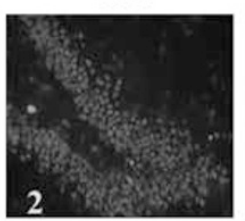

PBR

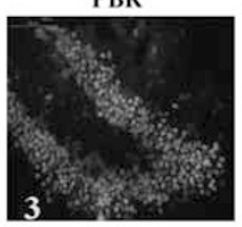

MBR
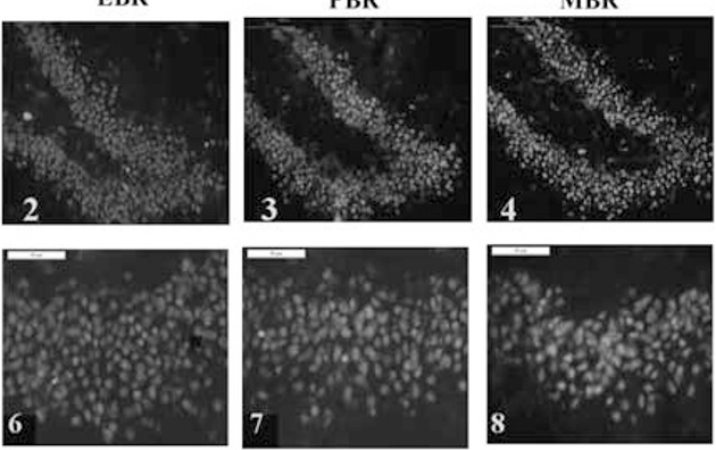

Figure 3 Effect of PSS exposure on NF- $\kappa$ B p50 immunoreactivity in the hippocampus subregions. Quantification of NF- $\kappa B$ p50 cells in the hippocampus CAI (a), CA3 (b), and DG (c) subregions of naive unexposed rats and rats exposed to predator scent stress. Representative photographs of p50 immunoreactivity in the hippocampal CAI, CA3, and DG of animals in the naive control $(I)(n=6)$, EBR $(2)(n=9), \operatorname{PBR}(3)(n=6)$, and MBR (4) $(n=6)$ groups. Photographs were acquired at $\times 50$ magnification. Scale bar, $50 \mu \mathrm{m}$. The cells in red were p50 positive. A single I0-min exposure to PSS significantly increased NF- $\kappa$ B p50 levels in the DG in EBR and PBR groups compared with unexposed controls. In the CAI and CA3 subregions, no significant differences were found between exposed animals and controls. Results displayed as mean \pm SEM. DG, dentate gyrus; CAI, cornu ammonis I; EBR, extreme behavioral response; MBR, minimal behavioral response; PBR, partial behavioral response; PSS, predator scent stress. The color reproduction of this figure is available at the Neuropsychopharmacology journal online.

expression in the EBR group compared with controls $(p<0.001, p<0.01$, and $p<0.0001)$. In DG, PSS also decreased phospho-p38 expression in EBR compared with MBR animals $(p<0.005)$. In CA3, PSS also decreased phospho-p38 expression in PBR animals compared with controls $(p<0.0002$ and $p<0.002$, respectively).

\section{Behavioral Effects of Corticosterone Administration Immediately after PSS Exposure}

Elevated plus-maze. Two-way ANOVA revealed a significant PSS exposure and treatment effects in terms of time spent in open arms $(\mathrm{F}(1,36)=4.8, p<0.035$ and $\mathrm{F}(1,36)=$ $7.7, p<0.009$, respectively; Figure 8a). No effects were observed for PSS exposure-treatment interaction. In terms of open arm entries, two-way ANOVA revealed significant effects of PSS exposure and treatment $(\mathrm{F}(1,36)=6.4$, $p<0.016$ and $\mathrm{F}(1,36)=5.6, p<0.024$, respectively; Figure $8 \mathrm{~b}$ ). No effects were observed for PSS exposure-treatment interaction. In terms of anxiety index, two-way ANOVA revealed significant effects of exposure and treatment $(\mathrm{F}(1,36)=5.3$, $p<0.03$ and $\mathrm{F}(1,36)=9.4, p<0.004$, respectively; Figure $8 \mathrm{~d}$ ). No effects were observed for PSS exposure-treatment interaction. Bonferroni test confirmed that exposed group treated with saline exhibited a significant decrease in overall time spent in the open arms and in open arm entries and a significantly increased anxiety index compared with unexposed vehicletreated rats and exposed rats treated with corticosterone (Bonferroni test: time open: $p<0.0035$ and $p<0.045$; open entries: $p<0.02$ and $p<0.025$; anxiety index: $p<0.05$ and $p<0.015$, respectively). No differences were observed in overall time spent in the open arms of the maze or in open arm entries or in the anxiety index between PSS-exposed animals treated with corticosterone and unexposed vehicle or corticosterone 

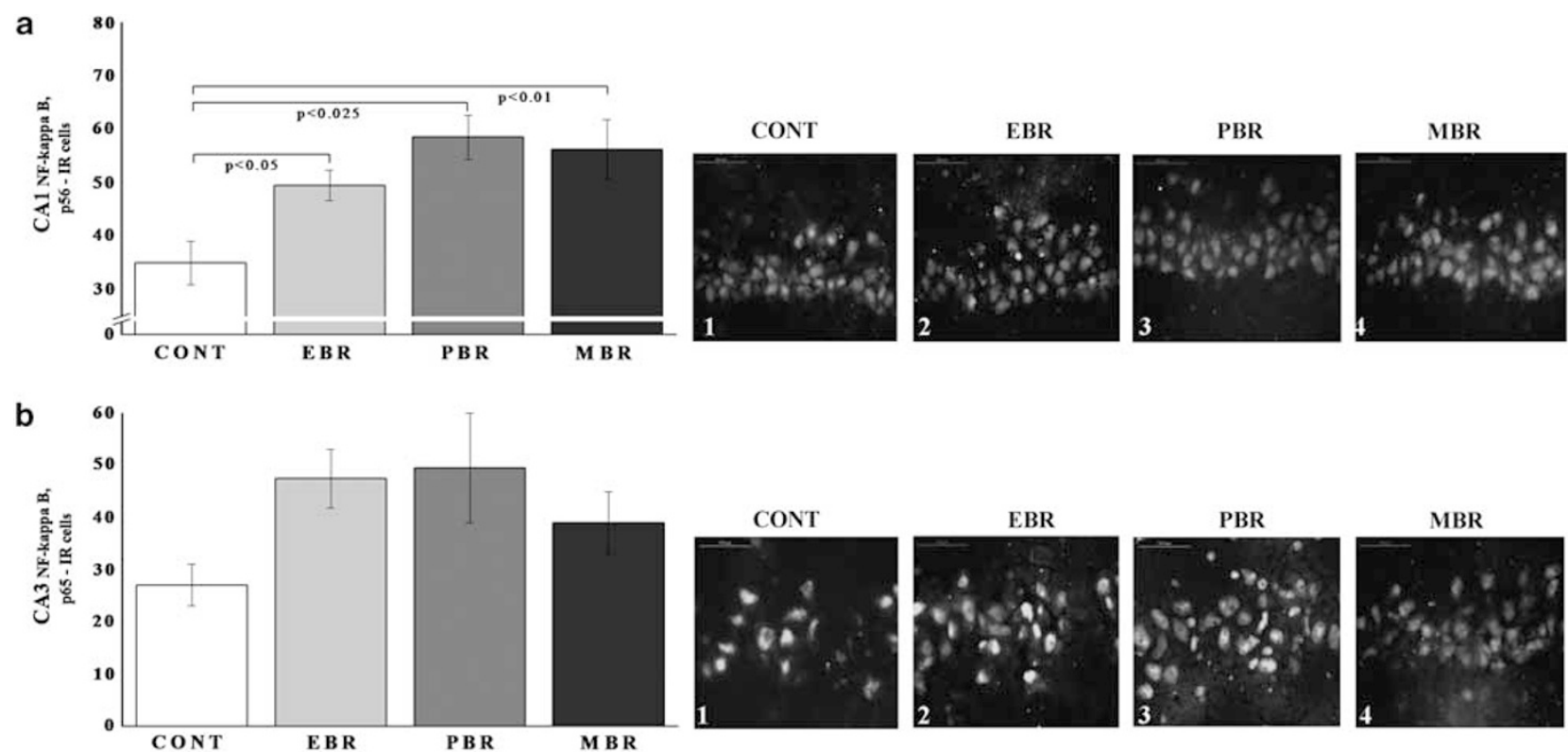

C
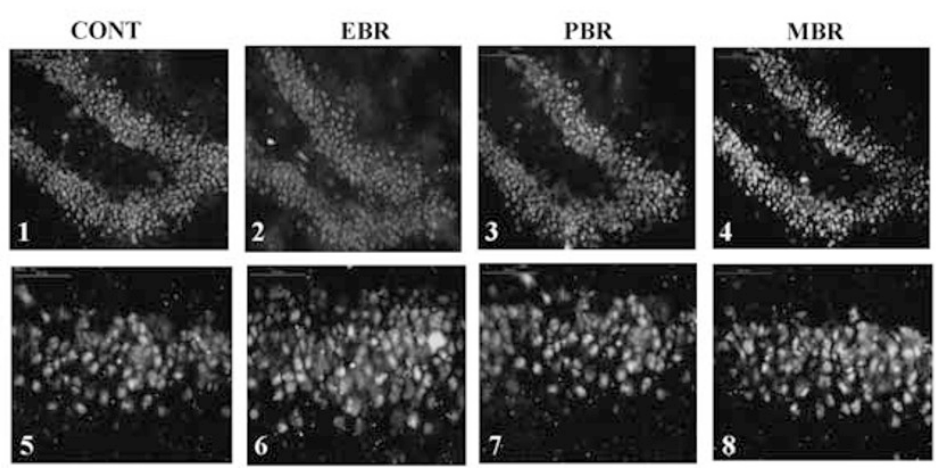

Figure 4 Effect of PSS exposure on NF- $\kappa$ B p 65 immunoreactivity in the hippocampus subregions. Quantification of NF- $\kappa$ B p 65 cells in the hippocampus CAI (a), CA3 (b), and DG (c) subregions of naive unexposed rats and rats exposed to predator scent stress. Representative photographs of p65 immunoreactivity in the hippocampal CAI, CA3, and DG of animals in the naive control (I) $(n=6)$, EBR $(2)(n=9), \operatorname{PBR}(3)(n=6)$, and MBR $(4)(n=6)$ groups. Photographs were acquired at $\times 50$ magnification. Scale bar, $50 \mu \mathrm{m}$. The cells in green were p65 positive. PSS significantly increased CAI NF- $\kappa$ B p65 levels in all exposed animals compared with controls and increased DG p65 levels in EBR animals compared with controls, MBR, and PBR animals. In the CA3 hippocampal subregions, no significant differences were found between exposed animals and controls. All data represent group mean \pm SEM. DG, dentate gyrus; CAI, cornu ammonis I; EBR, extreme behavioral response; MBR, minimal behavioral response; PBR, partial behavioral response; PSS, predator scent stress. The color reproduction of this figure is available at the Neuropsychopharmacology journal online.

controls. No differences were observed in total exploration on the maze among groups (Figure 8c).

Startle response. Two-way ANOVA revealed a significant effect for PSS exposure $(\mathrm{F}(1,36)=22.2, p<0.0001)$ and a treatment effect $(\mathrm{F}(1,36)=8.9, p<0.005)$. Bonferroni test confirmed that exposed group treated with vehicle showed a significantly increased mean startle amplitude compared with unexposed controls $(p<0.0001)$ and exposed rats treated with corticosterone $(p<0.05$; Figure 8e) When treated with corticosterone, members of the exposed group exhibited significant increases in mean startle amplitude compared with unexposed rats treated with corticosterone $(p<0.0001)$.

Startle habituation. Two-way ANOVA revealed a significant effect for PSS exposure $(\mathrm{F}(1,36)=104.5, p<0.0001)$ and an exposure-treatment interaction effect $(\mathrm{F}(1,36)=$ 14.2, $p<0.0006$; Figure 8f). Bonferroni test confirmed that
PSS exposure caused a significant deficit in habituation in exposed animals treated with vehicle compared with unexposed groups $(p<0.0001)$ and exposed rats treated with corticosterone $(p<0.015)$ PSS exposure caused a significant deficit in habituation in exposed animals treated with corticosterone compared with unexposed rats treated with corticosterone $(p<0.0001)$.

Relative prevalence rates according to $C B C$. There were significant differences in the prevalence rates of individuals displaying EBR among groups (Pearson's $\chi^{2}=9.73, \mathrm{df}=3$, $p<0.025$ ). The prevalence of EBR individuals among PSSexposed rats injected with vehicle was $30 \%$ of the total population, a marked difference from the rates observed in the unexposed and in the PSS-exposed groups treated with corticosterone, both of which lacked EBR individuals (Figure $8 \mathrm{~g}$ ). There were no significant differences in the prevalence of either MBR (Figure $8 \mathrm{~h}$ ) or PBR among groups (Figure $8 \mathrm{i}$ ). 

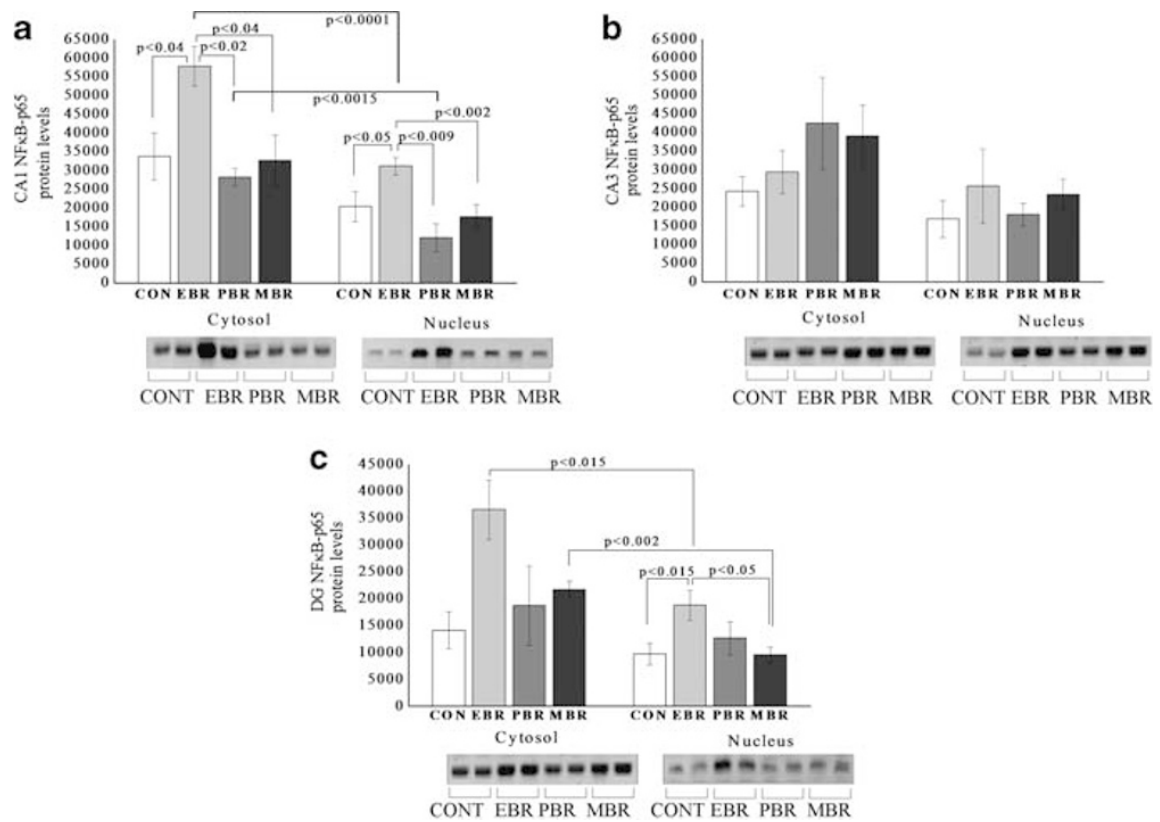

Figure 5 PSS exposure increased p65 translocation to the nucleus 7 days post-PSS exposure. Western blot analysis of p65 protein levels in densitometry values and representative gels (lower panels) in the cytosolic and nuclear fractions of hippocampal CAI (a), CA3 (b), and DG subregions (c) of naive control $(n=6), \operatorname{EBR}(2)(n=6), \operatorname{PBR}(3)(n=6)$, and MBR (4) $(n=6)$ groups. Cytosolic fraction: in the CAI subregion, p65 protein levels were significantly higher in the EBR animals when compared with controls, PBR, and MBR animals. Nuclear fraction: In the CAI and DG subregions, p65 protein levels were significantly higher in the EBR animals when compared with controls and MBR animals. Each group contains duplicate lanes. Densitometry values are means of 3-5 gels. All data represent group mean \pm SEM. CON, control; EBR, extreme behavioral response; MBR, minimal behavioral response; PBR, partial behavioral response.

\section{Effects of Immediate Post-Exposure Corticosterone Administration on NF- $\kappa$ B Expression}

Administration of corticosterone immediately after exposure to stress significantly decreased expression of p50 $(\mathrm{F}(1,18)=5.9, p<0.0025$; Figure 9a) and $\mathrm{p} 65(\mathrm{~F}(1,18)=$ $12.8, p<0.002$; Figure $9 \mathrm{~b}$ ) subunits in the DG areas compared with exposed animals treated with vehicle (Bonferroni test: $p<0.05$ and $p<0.004$, respectively) No differences were observed between the exposed groups in either the CA1 or CA3 area.

\section{Effects of Corticosterone Administered Immediately after Exposure on I- $\kappa \mathrm{B} \alpha, \mathrm{p} 38 /$ phospho-p38 Expression}

Administration of corticosterone post exposure significantly increased expression of $I-\kappa \mathrm{B} \alpha$ in the CA3 $(\mathrm{F}(1,12)=$ 9.8, $p<0.01)$ and DG $(\mathrm{F}(1,12)=4.6, p<0.05)$ compared with exposed animals treated with vehicle (Figure 10a-c). Administration of corticosterone significantly increased expression of p38 and phospho-p38 in the CA1 $(\mathrm{F}(1,18)=$ $8.5, p<0.045$ and $\mathrm{F}(1,18)=22.7, p<0.0002$, respectively), CA3 $(\mathrm{F}(1,18)=16.4, p<0.0008$ and $\mathrm{F}(1,18)=35.7, p<0.0001$, respectively), and DG $(\mathrm{F}(1,18)=37.4, p<0.0001$ and $\mathrm{F}(1,18)=$ $31.4, p<0.00035$, respectively) compared with exposed animals treated with vehicle (Figure 10d-i).

\section{Behavioral Effects of PDTC Administration Immediately after PSS Exposure}

Elevated plus-maze. Two-way ANOVA revealed significant treatment and exposure-treatment interaction effects in terms of time spent in open arms $(\mathrm{F}(1,32)=11.3, p<0.025$ and $F(1,32)=6.1, p<0.02$, respectively; Figure 11a). No effects were observed for PSS exposure. In terms of open arm entries, two-way ANOVA revealed significant effects of PSS exposure and treatment $(\mathrm{F}(1,32)=4.4, p<0.056$ and $\mathrm{F}(1,32)=11.0, p<0.002$, respectively; Figure $11 \mathrm{~b}$ ). No effects were observed for PSS exposure-treatment interaction. In terms of total activity on the maze, two-way ANOVA revealed significant effects of treatment $(\mathrm{F}(1,32)=$ 5.8, $p<0.025$; Figure 11c). No effects were observed for exposure and exposure-treatment interaction. In terms of anxiety index, two-way ANOVA revealed significant effects of exposure, treatment, and exposure-treatment interaction $(\mathrm{F}(1,32)=5.6, \quad p<0.025 ; \quad \mathrm{F}(1,32)=12.4, \quad p<0.001 ; \quad$ and $\mathrm{F}(1,32)=10.0, p<0.003$, respectively; Figure 11d). Bonferroni test confirmed that exposed group treated with saline exhibited a significant decrease in overall time spent in the open arms and in open arm entries and a significantly increased anxiety index compared with unexposed vehicletreated rats and exposed rats treated with PDTC (Bonferroni test: time open: $p<0.0065$ and $p<0.0033$; open entries: $p<0.003$ and $p<0.0006$; anxiety index: $p<0.0005$ and $p<0.0001$, respectively). No differences were observed in overall time spent in the open arms of the maze or in open arm entries or in the anxiety index between PSS-exposed animals treated with PDTC and unexposed vehicle or PDTC controls.

Startle response. Two-way ANOVA revealed a significant effect for PSS exposure $(\mathrm{F}(1,32)=25.5, p<0.0001)$, a treatment effect $(\mathrm{F}(1,32)=7.5, p<0.0001)$, and an exposure-treatment interaction effect $(\mathrm{F}(1,32)=10.3, p<0.003)$. Bonferroni test confirmed that exposed group treated with 

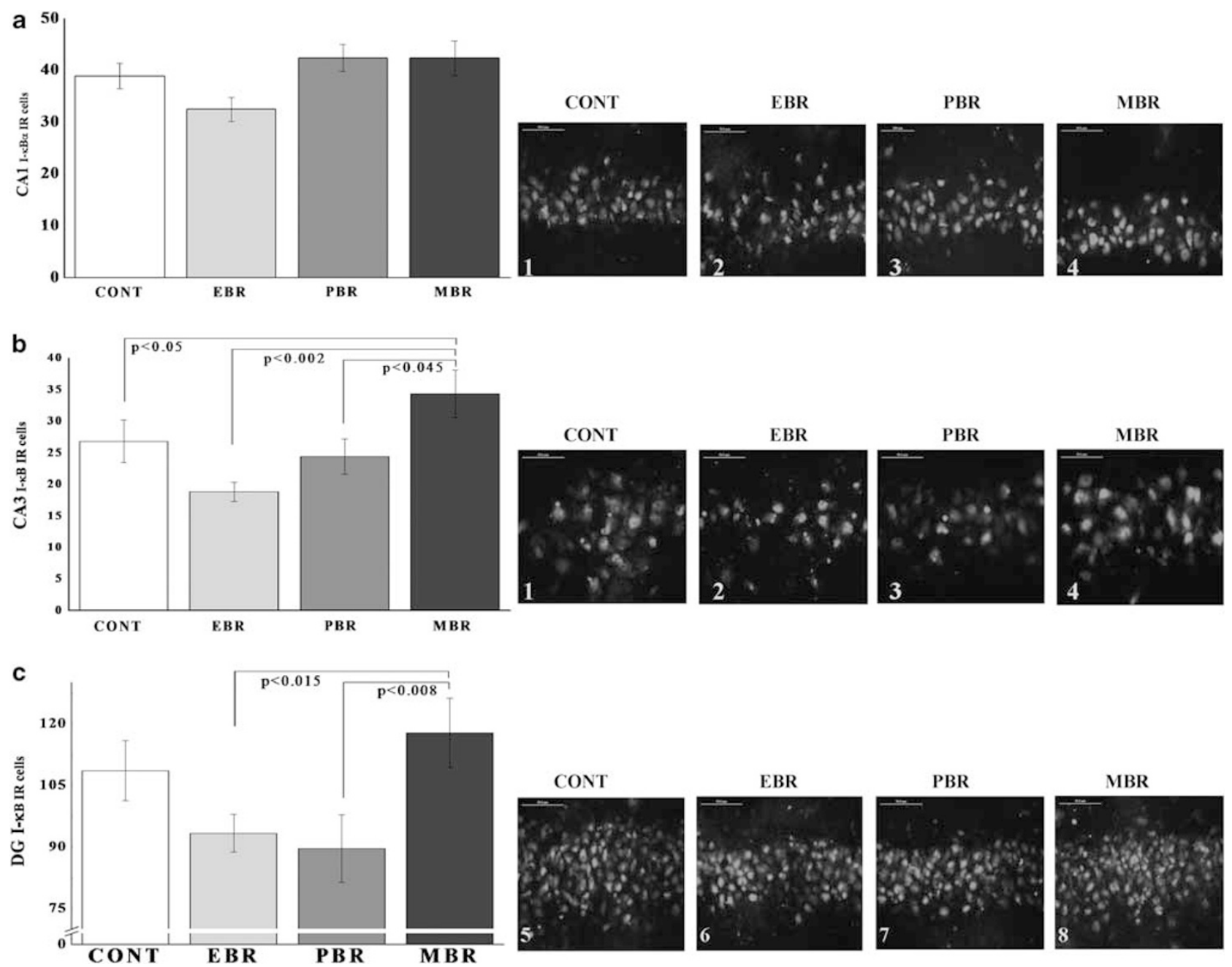

Figure 6 Effect of PSS exposure on $1-\kappa \mathrm{B} \alpha$ immunoreactivity in the hippocampus subregions. Quantification of $\mathrm{I}-\kappa \mathrm{B} \alpha$ cells in the hippocampus CAI (a), CA3 (b), and DG (c) subregions of naive unexposed rats and rats exposed to predator scent stress. Representative photographs of $I-\kappa B$ immunoreactivity in the hippocampal CAI, CA3, and DG of animals in the naive control (I) $(n=10)$, EBR (2) $(n=9)$, PBR (3) $(n=10)$, and MBR (4) ( $n=9)$ groups. Photographs were acquired at $\times 50$ magnification. Scale bar, $50 \mu \mathrm{m}$. The cells in red were $1-\kappa B \alpha$ positive. A single I0-min exposure to PSS significantly increased CA3 and DG expression of $\mathrm{I}-\kappa \mathrm{B} \alpha$ levels in MBR animals compared with EBR and PBR animals. All data represent group mean \pm SEM. DG, dentate gyrus; CAI, cornu ammonis I; EBR, extreme behavioral response; MBR, minimal behavioral response; PBR, partial behavioral response; PSS, predator scent stress. The color reproduction of this figure is available at the Neuropsychopharmacology journal online.

vehicle showed a significantly increased mean startle amplitude compared with unexposed controls $(p<0.0001$; Figure 11e). Exposed animals treated with PDTC exhibited significantly decreased mean startle amplitude compared with exposed animals treated with vehicle $(p<0.0002)$.

Startle habituation. Two-way ANOVA revealed a significant effect for PSS exposure $(\mathrm{F}(1,32)=27.7, p<0.0001)$ and an exposure-treatment interaction effect $(\mathrm{F}(1,32)=4.2$, $p<0.05$; Figure 11f). Bonferroni test confirmed that exposed animals treated with PDTC exhibited significantly increased startle habituation compared with exposed animals treated with vehicle $(p<0.015)$.

Relative prevalence rates according to $C B C$. There were significant differences in the prevalence rates of individuals displaying EBR among groups (Pearson's $\chi^{2}=9.8, \mathrm{df}=3$, $p<0.025)$. The prevalence of EBR individuals among
PSS-exposed rats injected with vehicle was $44.4 \%$ of the total population, a marked difference from the rates observed in the unexposed and in the PSS-exposed groups treated with PDTC, both of which lacked EBR individuals (Figure 11g). There were no significant differences in the prevalence of either MBR (Figure 11h) or PBR among groups (Figure 11i).

\section{Effects of Immediate Post-Exposure PDTC Administration on NF- $\kappa$ B Expression}

Administration of PDTC immediately after PSS exposure significantly decreased expression of p50 in the DG subregion $(\mathrm{F}(1,18)=5.7, p<0.03$; Figure $12 \mathrm{~b})$ and significantly decreased expression of p65 in the CA1 $(\mathrm{F}(1,18)=18.0$, $p<0.0005$; Figure 12c) and $\mathrm{DG}(\mathrm{F}(1,18)=4.9, p<0.04$; Figure 12e) subregions compared with exposed animals treated with vehicle. No differences were observed between the exposed groups in the CA3 subregion. 

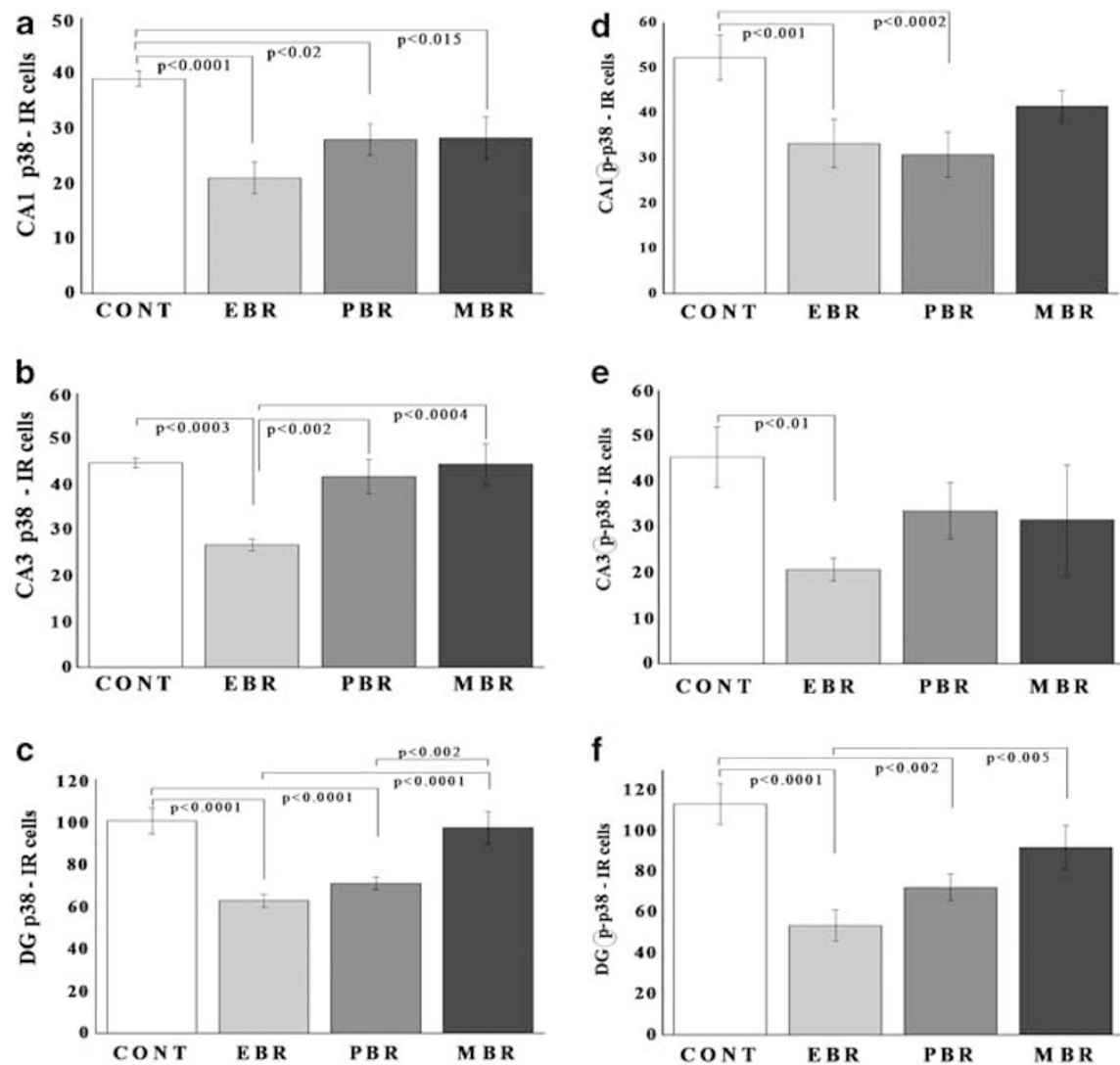

Figure 7 Effect of PSS exposure on p38 and phospho-p38 immunoreactivity in the hippocampus subregions. Quantification of p38 and phospho-p38 cells in the hippocampus CAI (a, d), CA3 (c, e), and DG (e, f) subregions of naive unexposed rats $(n=8)$, EBR $(n=8)$, PBR $(n=8)$, and MBR $(n=8)$ groups. PSS exposure significantly decreased CAI and DG expression of p38 and phospho-p38 in all the exposed animals when compared with unexposed controls. In the CA3 subregion, PSS decreased expression of p38 and phospho-p38 only in the EBR animals. Results displayed as mean \pm SEM. DG, dentate gyrus; CAI, cornu ammonis I; EBR, extreme behavioral response; MBR, minimal behavioral response; PBR, partial behavioral response; PSS, predator scent stress.

\section{Effects of PDTC Administered Immediately after Exposure on $\mathrm{I}-\kappa \mathrm{B} \alpha, \mathrm{p} 38 / \mathrm{phospho-p38}$ Expression}

Administration of PDTC significantly increased expression of $I-\kappa B \alpha$ in the CA1 $(\mathrm{F}(1,13)=4.7, p<0.05)$ and DG $(\mathrm{F}(1,13)=8.5, p<0.015)$ compared with exposed animals treated with vehicle (Figure 10a-c). Administration of PDTC significantly increased expression of p38 and phospho-p38 in the CA1 $(\mathrm{F}(1,16)=7.6, p<0.015$ and $\mathrm{F}(1,16)=$ 9.5, $p<0.0075$, respectively), CA3 $(\mathrm{F}(1,16)=6.7, p<0.025$ and $\mathrm{F}(1,16)=5.2, p<0.04$, respectively), and $\mathrm{DG}(\mathrm{F}(1,16)=$ $29.5, p<0.0007$ and $\mathrm{F}(1,16)=18.7, p<0.0006$, respectively) compared with exposed animals treated with vehicle (Figure 13d-i).

\section{DISCUSSION}

We looked at critical signaling molecules (NF- $\kappa \mathrm{B}, \mathrm{I}-\kappa \mathrm{B} \alpha$, and $\mathrm{p} 38 /$ phospho-p38) to obtain an integrated picture of neuro-immune-endocrine modulation in stress-related responses. The development of an extreme (PTSD-like) longterm behavioral response pattern at 1 week after exposure to stress was found to be associated with a distinct pattern of long-term excessive expression of the NF- $\kappa \mathrm{B}$ complex with concomitant downregulation in the expression of $\mathrm{I}-\kappa \mathrm{B} \alpha$, and $\mathrm{p} 38$ and phospho-p 38 mitogen-activated protein kinase (MAPK) molecular signaling in hippocampal structures. Pharmacological manipulation of NF- $\kappa \mathrm{B}$ complex by administration of a single high dose of corticosterone or a selective NF- $\kappa$ B inhibitor immediately after stress exposure significantly reduced behavioral disruption, and concomitantly normalized the molecular pathway response, that is, downregulated $\mathrm{NF}-\kappa \mathrm{B}$ subunits and upregulated $\mathrm{I}-\kappa \mathrm{B} \alpha$ and $\mathrm{p} 38 /$ phospho-p38 MAPK molecular signaling. Therefore, NF- $\kappa$ B complex is actively involved in the neurobiological response to PSS.

The initial stage of the study examining local brain levels of p50 and p 65 subunits of NF- $\kappa \mathrm{B}$ in stress-exposed animals revealed that at 7 days after exposure, p50 and p65 levels in the DG subregion were upregulated in animals whose behavior was severely affected by the stressor (EBR), whereas MBR animals and controls displayed no change in either p50 or p65 expression. This NF- $\kappa$ B upregulation was accompanied by translocation of the p65 subunit into the nucleus. Thus, in the EBR animals NF- $\kappa \mathrm{B}$ is activated within the neurons in the hippocampus subregions. The implications of these finding were unclear. Depending on context and sequential factors, the NF- $\kappa \mathrm{B}$ complex has been associated with both neurotoxic and neuroprotective properties. Hence, the significance of the localized findings characterizing extreme responders require further elucidation. They could be a marker (or a component) of required changes in neural plasticity and synaptic function in response to stresses or a marker of pathological processes. 

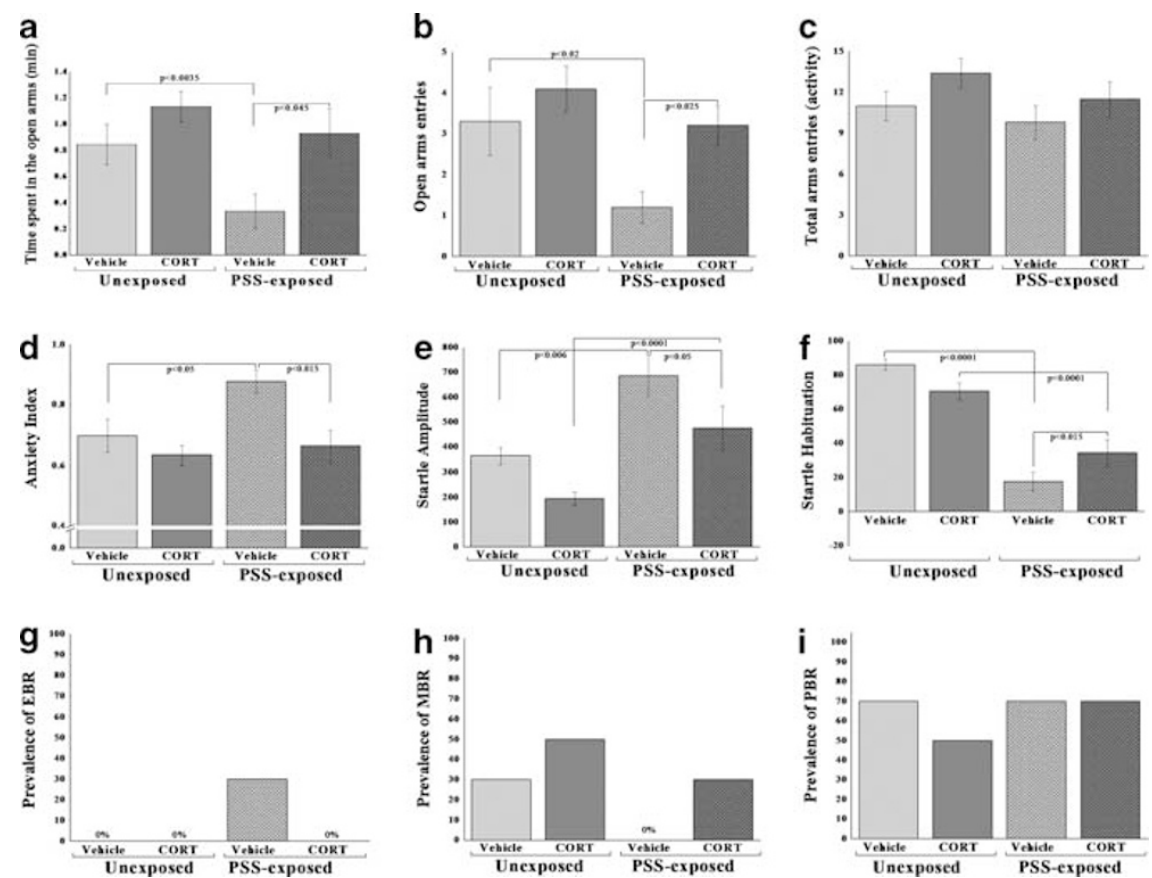

Figure 8 Effect of early post-stressor intervention with high-dose corticosterone on behavioral stress responses. A single I0-min exposure to PSS followed by immediate administration of high dose $(25.0 \mathrm{mg} / \mathrm{kg}$ ) corticosterone significantly increased the time spent in the open arms (a) and the number of entries to the open arms of the maze (b) and decreased anxiety index (d) when compared with vehicle treatment. Immediate corticosterone administration reduced the response to the stimulus (startle amplitude) (e) and significantly reversed the stress-induced habituation (f) deficit found in vehicle-treated rats, exposure-treatment interaction. Early treatment with high-dose corticosterone reduced the prevalence of PTSD-like behavioral responses (EBR) (g) relative to vehicle control treatment. No differences were observed in total exploration on the maze (c) and in the prevalence of minimal behavioral responders (h) or partial behavioral responses (i). All data represent group mean \pm SEM.
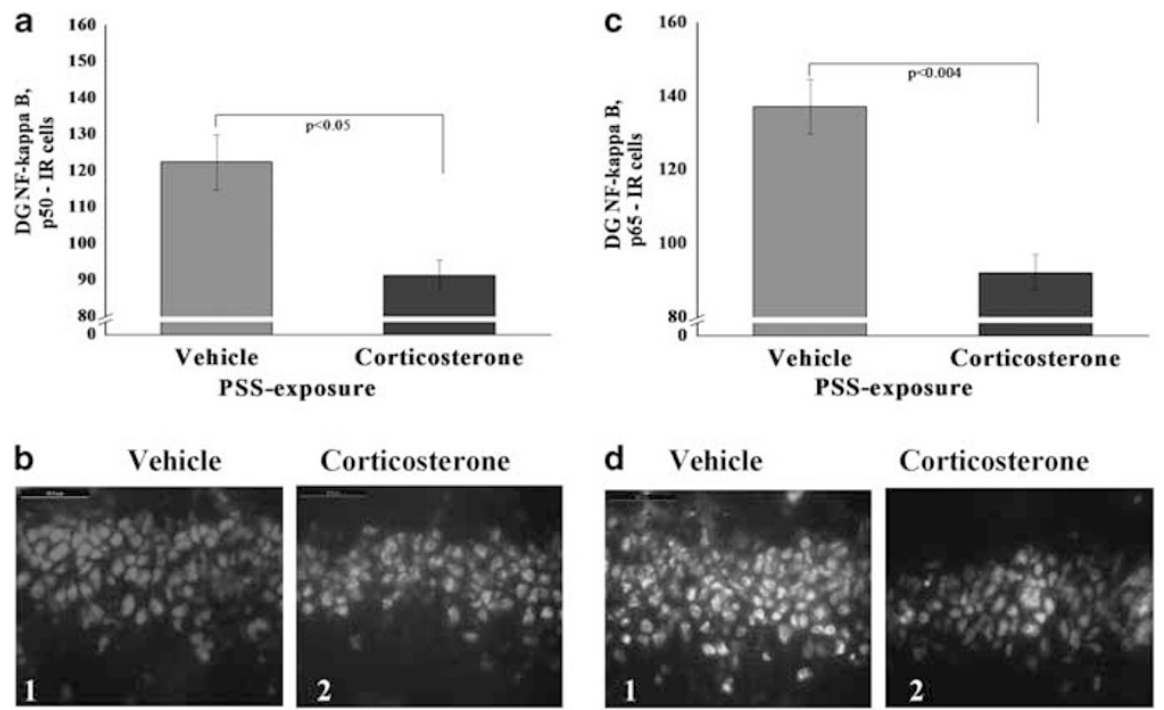

Figure 9 Effect of early post-stressor intervention with high-dose corticosterone on NF- $\kappa \mathrm{B}$ p50 and p65 immunoreactivity in the hippocampus. (a) The quantitative analysis of p50 subunit immunostaining in the DG area of exposed rats treated with high-dose corticosterone or vehicle. (b) Representative photographs of NF- $\kappa \mathrm{B}$ p50 immunoreactivity in the DG of exposed animals treated with high-dose corticosterone (2) or vehicle (I). Photographs were acquired at $\times 40$ magnification. Scale bar, $50 \mu \mathrm{m}$. The cells in red were p50 positive and in green were p65 positive. (c) The quantitative analysis of p65 subunit immunostaining in the DG area of exposed rats treated with high-dose corticosterone or vehicle. (d) Representative photographs of NF- $\kappa \mathrm{B}$ p65 immunoreactivity in the DG of exposed animals treated with high-dose corticosterone (2) or vehicle (I). Photographs were acquired at $\times 40$ magnification. Scale bar, $50 \mu \mathrm{m}$. The cells in white were p50 positive. Administration of high-dose corticosterone immediately post exposure significantly decreased expression of NF- $\kappa \mathrm{B}$ p50 and p65 subunits in the DG when compared with exposed animals treated with vehicle. All data represent group mean \pm SEM. DG, dentate gyrus; CAI, cornu ammonis I; EBR, extreme behavioral response; MBR, minimal behavioral response; PBR, partial behavioral response; PSS, predator scent stress. The color reproduction of this figure is available at the Neuropsychopharmacology journal online. 

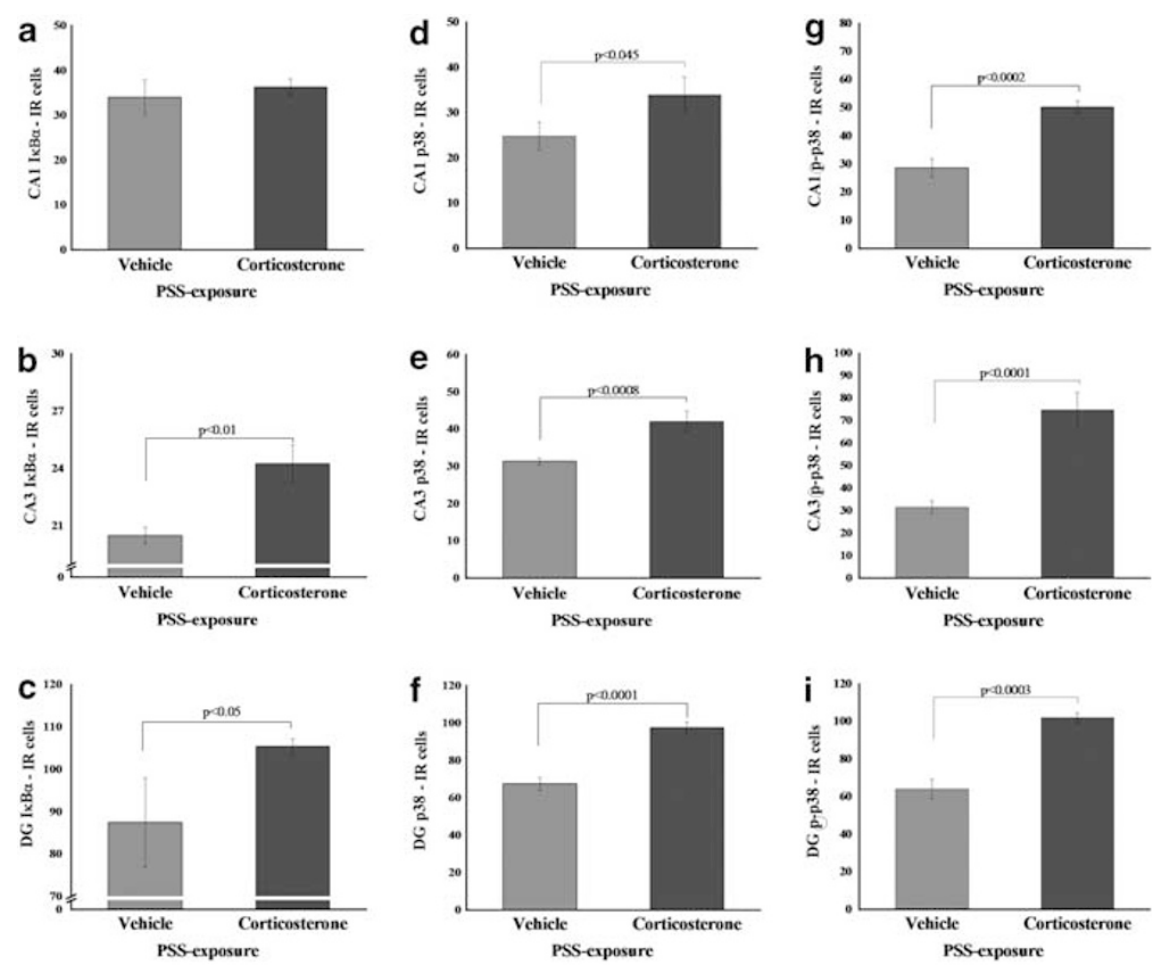

Figure 10 Effect of early post-stressor intervention with high-dose corticosterone on $1-\kappa \mathrm{B} \alpha, \mathrm{p} 38$, and phospho-p38 immunoreactivity in the hippocampal subregions. Quantification of $\mathrm{l}-\kappa \mathrm{B} \alpha, \mathrm{p} 38$, and phospho-p38 cells in the hippocampus CAI (a, d, g), CA3 (b, e, h), and DG (c, f, i) subregions of exposed rats treated with saline $(n=10)$, and exposed rats treated with high-dose corticosterone $(n=10)$. Administration of high-dose corticosterone immediately after exposure significantly increased expression of p38 and phospho-p38 in the hippocampal CAI area, CA3, and DG when compared with exposed animals treated with vehicle. Administration of high-dose corticosterone significantly increased expression of I- $\kappa \mathrm{B} \alpha$ in the CA3 and DG when compared with exposed animals treated with vehicle. Scale bar, $10 \mu \mathrm{m}$. All data represent group mean \pm SEM. DG, dentate gyrus; CAI, cornu ammonis I; EBR, extreme behavioral response; MBR, minimal behavioral response; PBR, partial behavioral response; PSS, predator scent stress.

Previously, we reported that at 7 days after PSS exposure, EBR animals displayed significantly higher circulating corticosterone levels and a significant elevation in glucocorticoid receptor (GR) translocation to the nucleus in the hippocampal CA3 and DG regions compared with MBR individuals and controls (Kozlovsky et al, 2009). GR is a hormone-dependent transcription factor superfamily critically involved in mediating the immunosuppressive function of GCs by repressing the expression of major cytokine genes and their pleiotropic actions on target cells (Almawi and Melemedjian, 2002; Auphan et al, 1995; Majdalawieh and Ro, 2010; Scheinman et al, 1995). This immunosuppressive and anti-inflammatory action involves negative cross-talk between GR and other transcription factors such as NF- $\kappa$ B. In other words, the relationship between NF- $\kappa$ B and GR is mutually antagonistic in that NF- $\kappa \mathrm{B}$ can suppress the function of GR that, in turn, effectively inhibits NF- $\kappa$ B activation (McKay and Cidlowski, 1999; Scheinman et al, 1995; Szatmary et al, 2004). The goal of this regulatory interplay is to maintain homeostasis by avoiding excessive destruction and inflammation (Liberman et al, 2009). Hence, we expected excessive GCs to inhibit NF- $\kappa \mathrm{B}$ signaling in the hippocampus in the EBR animals. Thus, we did not expect the findings, rejecting our hypothesis, of the significantly increased levels of DG NF- $\kappa$ B subunits we observed in the EBR individuals but not in control or MBR rats.

A proposed molecular mechanism of NF- $\kappa \mathrm{B} / \mathrm{GR}$ antagonism is via stimulation of $\mathrm{I}-\kappa \mathrm{B}$ synthesis (Auphan et al, 1995;
Scheinman et al, 1995). In our investigation of the expression of I- $\kappa \mathrm{B} \alpha$ in the hippocampal subregions at 7 days post exposure, we showed that the MBR animals displayed significantly higher levels of I- $\kappa \mathrm{B} \alpha$ in the CA3 and DG subregions compared with EBR and PBR animals. Increased $\mathrm{I}-\kappa \mathrm{B}$ availability would result in its binding to, and sequestration of, NF- $\kappa \mathrm{B}$ in the cytosol, which reduces $\mathrm{NF}-\kappa \mathrm{B}$ nuclear translocation and attenuates NF- $\kappa \mathrm{B}$-driven transcriptional activities (Almawi and Melemedjian, 2002). In the DG, MBR animals displayed significantly higher levels of I- $\kappa \mathrm{B} \alpha$ than controls. Our findings suggest that I$\kappa \mathrm{B} \alpha$ downregulation in EBR animals may prevent repression of the NF- $\kappa \mathrm{B}$ complex and thus diminish the inhibition of NF- $\kappa \mathrm{B}$ transcriptional activities compared with MBR animals.

In addition to the classical I- $\kappa \mathrm{B}$ kinase/I- $\kappa \mathrm{B} \alpha$ pathway, the transcriptional activation of NF- $\kappa \mathrm{B}$ is also regulated by events that directly affect its activation (King et al, 2009). One family of kinases essential for signal transfer from the cell surface to the nucleus is MAPK. It has been shown that p38 and NF- $\kappa$ B are activated in response to similar stimuli and that $\mathrm{p} 38$ is required for NF- $\kappa \mathrm{B}$-dependent gene expression (Carter et al, 1999; Vanden Berghe et al, 1998). Karunakaran and Ravindranath (2009) demonstrated that phosphorylation of p38 is an important event upstream of NF- $\kappa \mathrm{B}$ activation. p38 is known to phosphorylate $\mathrm{I}-\kappa \mathrm{B} \alpha$ leading to its dissociation from the p65 subunit, thus facilitating the translocation of p65 to the nucleus (Calleros 

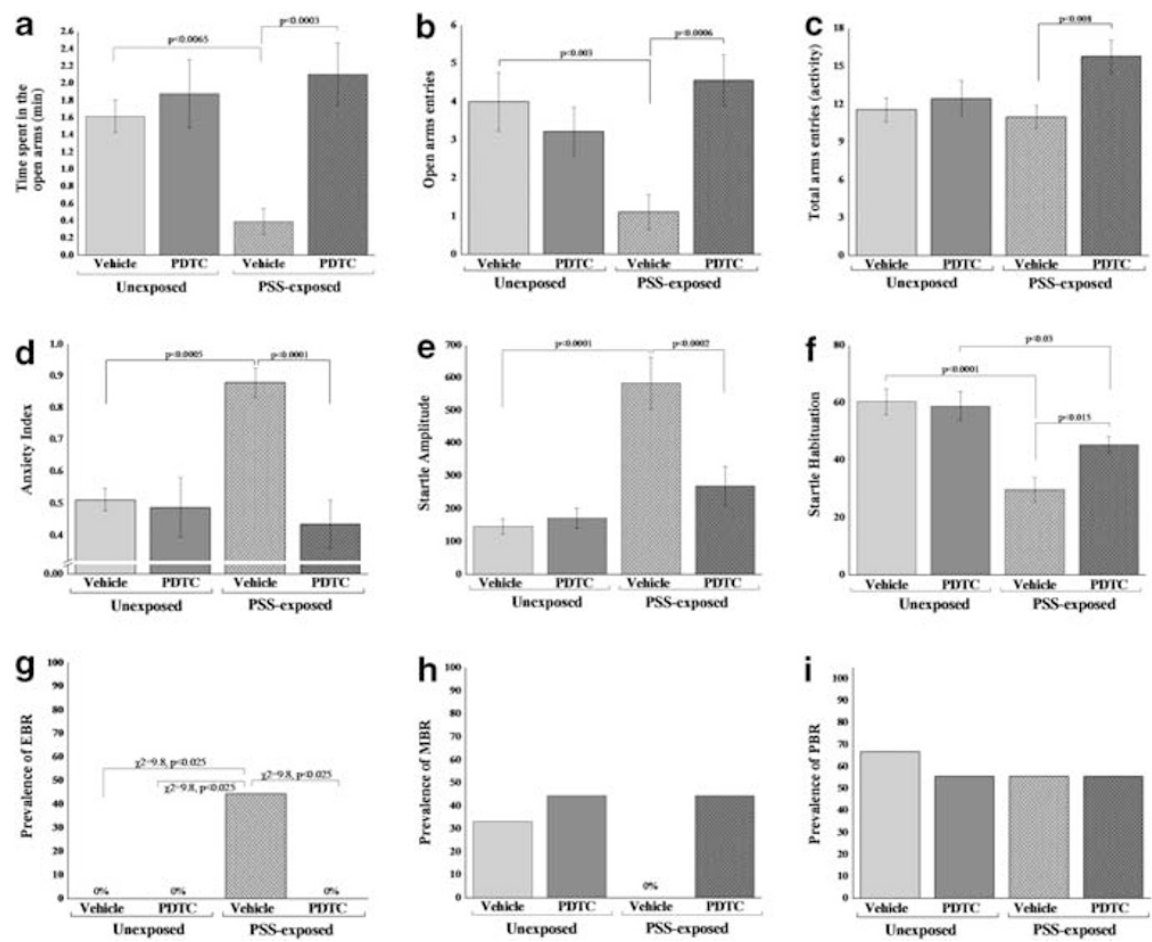

Figure II Effect of early post-stressor intervention with PDTC on behavioral stress responses. A single exposure to PSS followed by immediate administration of PDTC significantly increased the time spent in the open arms (a), the number of entries to the open arms (b), and decreased anxiety index (d) when compared with vehicle treatment. PDTC administration reduced the response to the stimulus (startle amplitude) (e) and reversed the stressinduced habituation ( $f$ ) deficit found in vehicle-treated rats, exposure-treatment interaction. Early treatment with TDTC reduced the prevalence of PTSDlike behavioral responses (EBR) (g) relative to vehicle control treatment. No differences were observed in the prevalence of minimal behavioral responders (h) or partial behavioral responses (i). All data represent group mean \pm SEM.

et al, 2006). Phosphorylated I- $\kappa \mathrm{B} \alpha$ was rapidly degraded by the proteasome (Finco and Baldwin, 1995). Moreover, it is now appreciated that at the cellular level the transcription factors NF- $\kappa$ B and GR have divergent effects (stimulatory $v s$ inhibitory, respectively) in gene expression. It has also been found that activation of $\mathrm{p} 38$ inhibits the transcriptional activation of GR (Szatmary et al, 2004). In our study, the EBR animals displayed significantly lower p38 and Phospho-p38 expression in the CA1, CA3, and DG hippocampal subregions compared with controls. EBR animals also displayed significantly lower p38 and phospho-p38 expression in the DG compared with MBR animals. As p38/ phospho-p38 are known to phosphorylate GR and inhibit its transcriptional activity (Szatmary et al, 2004), lower hippocampal levels of phospho-p38 should intensify $\mathrm{GC}$ action.

The finding that p38/phospho-p38 and I- $\kappa \mathrm{B} \alpha$ were upregulated in the DG subregion of minimally affected MBR rats, but not in PTSD-like EBR rats, suggests that the stress-induced upregulation of p38/phospho-p38 and I- $\kappa \mathrm{B} \alpha$ may be associated with adequate recovery processes and/or resilience, whereas a pattern of long-term excessive activation of the NF- $\kappa \mathrm{B}$ complex and GR pathways in the hippocampus appear to be associated with stress-related behavioral responses.

Previous reports support our finding. Madrigal et al (2001) reported that stress exposure increased NF- $\kappa$ B activation and subsequent NF- $\kappa \mathrm{B}$-dependent gene expression in the cortex of rats exposed to immobilization. They reported that the release of excitatory amino acidergic components induced by stress triggers the process of iNOS induction by stimulating the translocation of NF- $\kappa \mathrm{B}$ to the nucleus in brain cortex of rats exposed to acute restraint stress (Madrigal et al, 2001). Using an animal model of repeated trauma, Harvey et al (2005) investigated the effect of stress on the hippocampal NO-cGMP signaling pathway and its modulation using drugs selective for targets within the NMDA receptor cascade and NF- $\kappa$ B complex. Day 7 post stress revealed significantly increased hippocampal NO, which was blocked by NF- $\kappa \mathrm{B}$ antagonist (Harvey et al, 2005). Munhoz et al (2006) tested whether chronic, unpredictable stress modulated the effects of lipopolysaccharides on NF- $\kappa \mathrm{B}$ activity. They reported that CUS augmented the effect of LPS on NF- $\kappa \mathrm{B}$ activation in the frontal cortex and hippocampus. Moreover, CUS augmented the effect of LPS on expression of the proinflammatory genes IL- $\beta$, TNF- $\alpha$, and iNOS. Thus, stress or GCs can increase levels of proinflammatory cytokine in both the periphery and the brain. Increased NF- $\kappa \mathrm{B}$ activation has also been described in the lymphocytes of women stressed by the experience of undergoing a breast biopsy (Bierhaus et al, 2003), a crucial step in diagnosing a life-threatening disorder but also a situation characterized by anxiety and desperation comparable with other forms of psychosocial stress.

In order to assess whether the above NF- $\kappa \mathrm{B}$ patterns represented a marker of stress or a causal factor (indicating the direct involvement of NF- $\kappa \mathrm{B}$ in the stress response), 
a

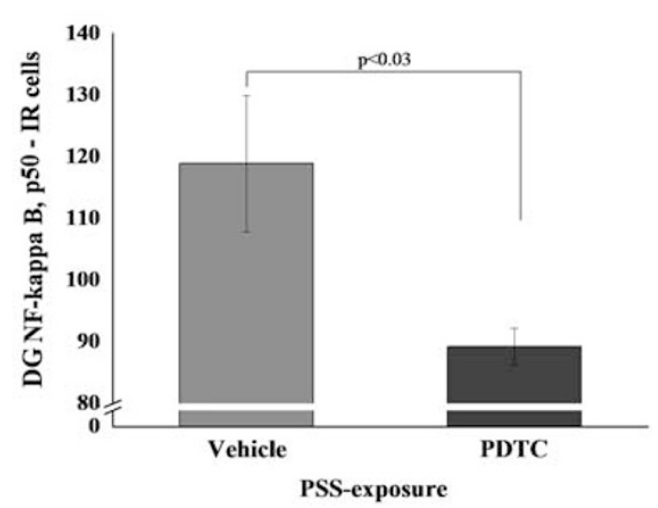

b
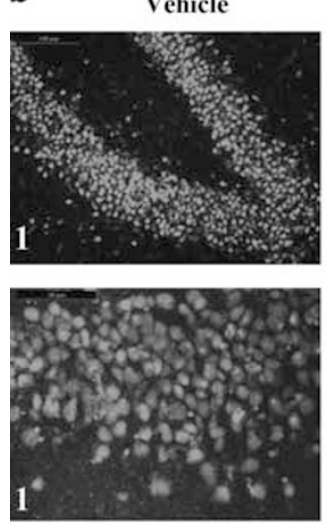

c
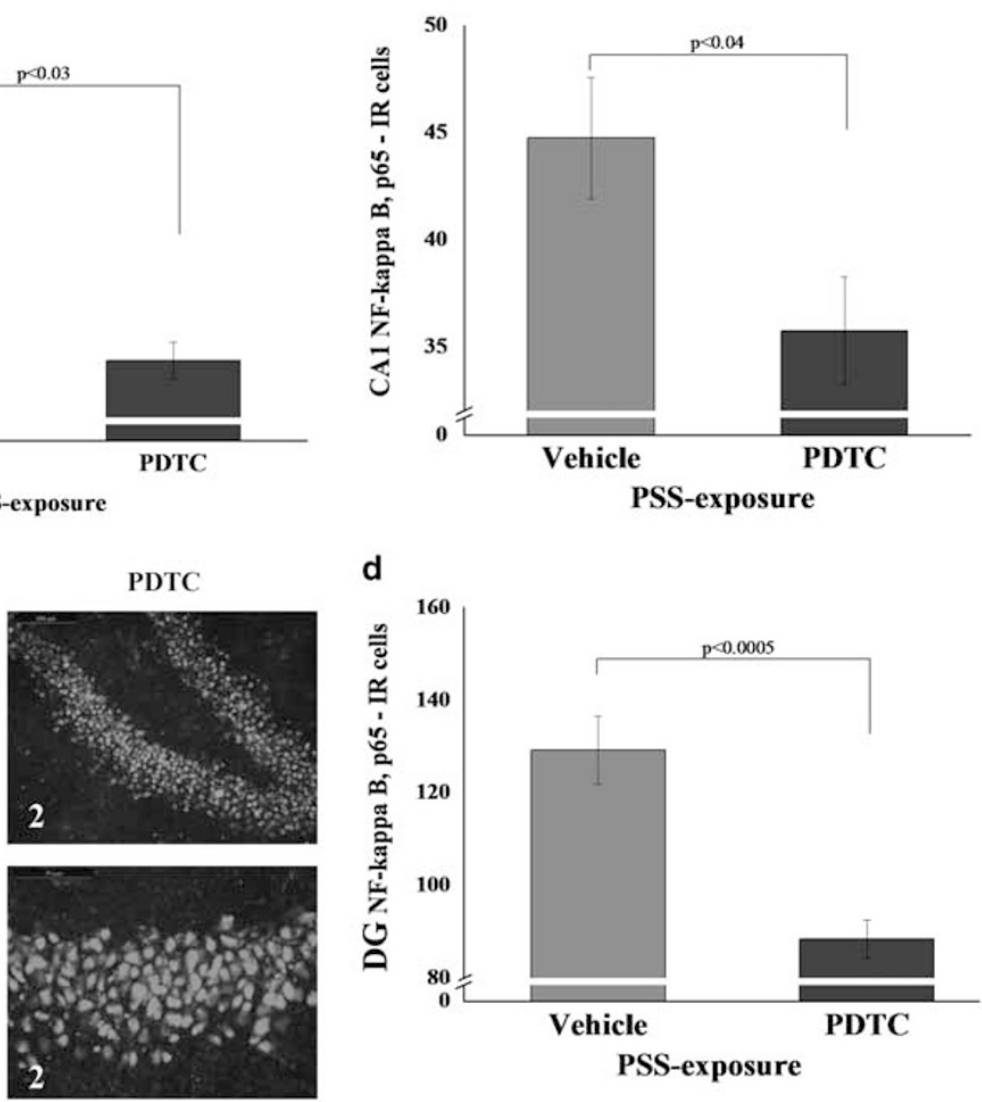

d

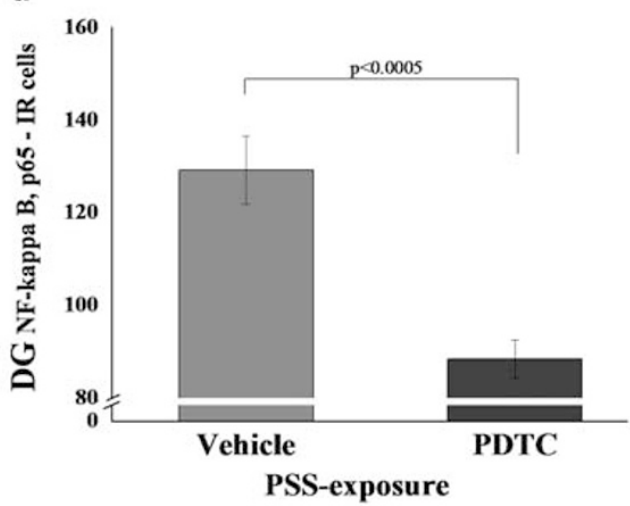

e PSS - Vehicle

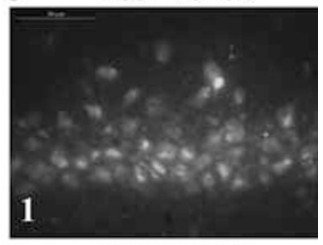

PSS - PDTC

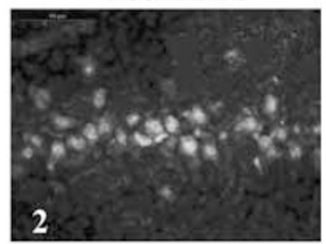

f

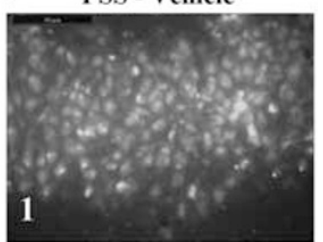

PSS - PDTC

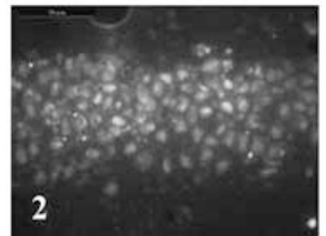

Figure 12 Effect of early post-stressor intervention with PDTC on NF- $\kappa$ B p50 and p65 immunoreactivity in the hippocampus. (a) The quantitative analysis of $p 50$ subunit immunostaining in the DG area of exposed rats treated with PDTC or vehicle. (b) Representative photographs of NF- $\kappa$ B p50 immunoreactivity in the DG of exposed animals treated with PDTC (2) or vehicle (I). Photographs were acquired at $\times 20($ Scale bar, I00 $\mu \mathrm{m})$ and $\times 40$ magnification (Scale bar, $50 \mu \mathrm{m}$ ). The cells in red were p50 positive. (c) The quantitative analysis of p65 subunit immunostaining in the CAI (c) and DG (d) areas of exposed rats treated with PDTC or vehicle. (e) Representative photographs of NF- $\kappa$ B p65 immunoreactivity in the CAI (e) and DG (f) of exposed animals treated with PDTC (2) or vehicle (I). Photographs were acquired at $\times 40$ magnification. Scale bar, $50 \mu \mathrm{m}$. The cells in green were p65 positive. Administration of high-dose corticosterone immediately post exposure significantly decreased expression of NF- $\kappa$ B p50 and p 65 subunits in the DG when compared with exposed animals treated with vehicle. All data represent group mean \pm SEM. DG, dentate gyrus; CAI, cornu ammonis I; EBR, extreme behavioral response; MBR, minimal behavioral response; PBR, partial behavioral response; PSS, predator scent stress. The color reproduction of this figure is available at the Neuropsychopharmacology journal online.

NF- $\kappa$ B levels were pharmacologically manipulated using two NF- $\kappa \mathrm{B}$ inhibitors: a single high-dose corticosterone or a specific NF- $\kappa$ B inhibitor, PDTC, immediately following stress exposure. A single $25 \mathrm{mg} / \mathrm{kg}$ dose of corticosterone administered immediately after PSS resulted, relative to untreated and placebo-treated controls, in reduced prevalence of EBR individuals - that is, a significant shift toward less extreme, stress-induced behavioral disruption- at 7 days with a concomitant increase in the prevalence of MBR individuals, compared with saline controls. The anxiolytic-like effect of high-dose corticosterone injected immediately after PSS exposure was accompanied by significant downregulation of the DG p50 and p65 subunits of the NF- $\kappa \mathrm{B}$ complex with concomitant upregulation of region-specific $\mathrm{I}-\kappa \mathrm{B} \alpha$ levels and their signaling pathways p38 and phospho-p38 compared with those given saline treatment.

One may speculate that high-dose corticosterone given immediately after PSS exposure activated the GC pathways. Activated GR is able to activate the p38/phospho-p38 MAPK signaling that may prevent the maladaptive influence of GCs on the brain via attenuation of GR function. Adequate GR signaling rescues the disrupted NF- $\kappa \mathrm{B}$ complex via direct pathways (ie, elevated I- $\kappa \mathrm{B} \alpha$ expression) or indirect molecular pathways (ie, elevated p38/phospo-p38 MAPK signaling).

Our results demonstrated that PDTC given immediately after PSS exposure activated p38/phospho-p38 MAPK pathway, upregulated region-specific I- $\kappa \mathrm{B} \alpha$ levels, and downregulated NF- $\kappa$ B subunits when compared with vehicle treatment. These results confirm the bulk of evidence indicating that PDTC prevented degradation of $\mathrm{I} \kappa \mathrm{B}-\alpha$ and NF- $\kappa \mathrm{B}$ nucleus translocation and thus inhibited NF- $\kappa \mathrm{B}$ activation (Cuzzocrea et al, 2002; Hayakawa et al, 2003; Liu et al, 1999; Schreck et al, 1992; Ziegler-Heitbrock et al, 1993). Pfeilschifter et al (2010) reported that PDTC potently reduces lesion volume in experimental animal model of stroke. The authors suggest that this effect may be mediated in part to a p38 MAPK pathway in brain endothelial cells (Pfeilschifter et al, 2010). 

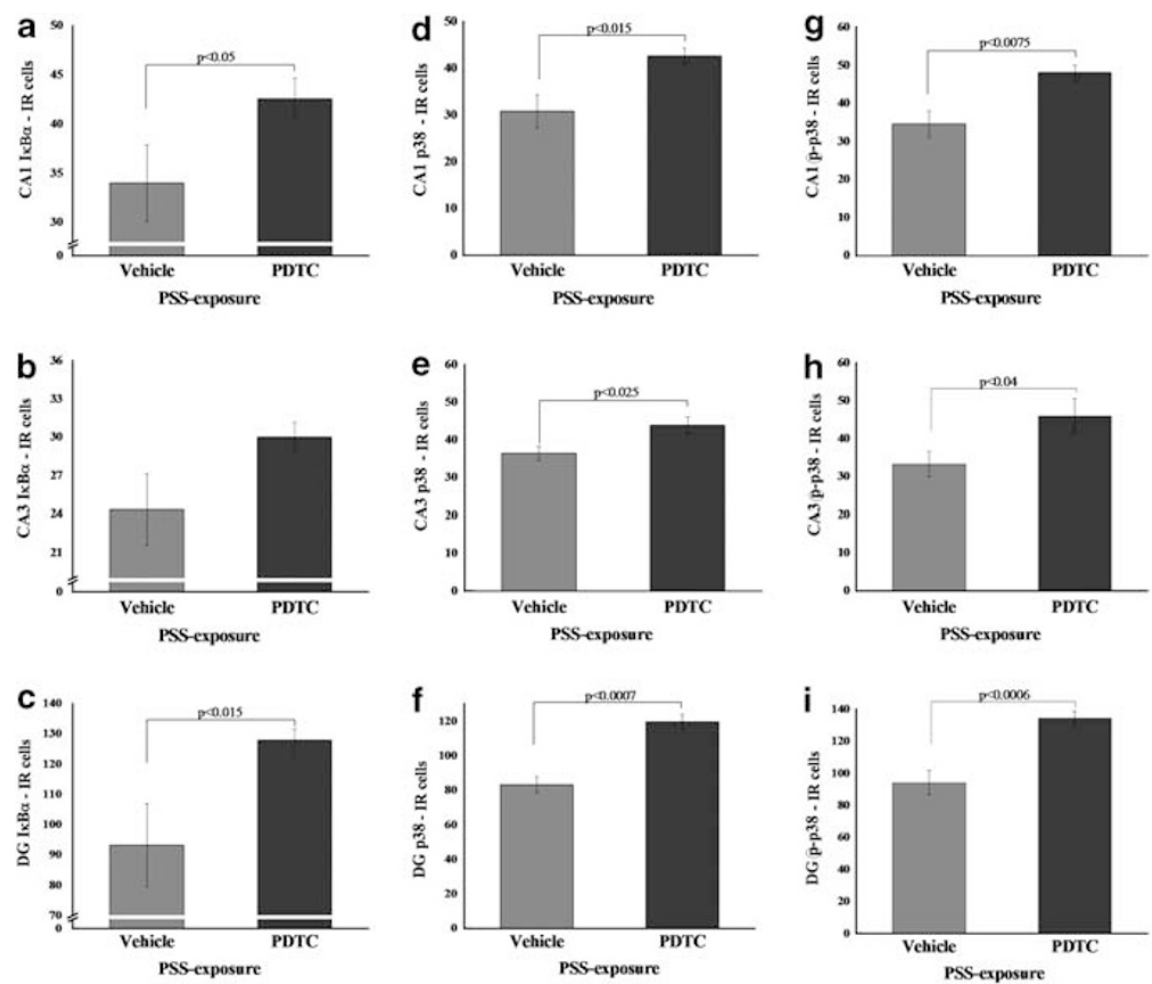

Figure 13 Effect of early post-stressor intervention with PDTC on $1-\kappa \mathrm{B} \alpha, \mathrm{p} 38$, and phospho-p38 immunoreactivity in the hippocampal subregions. Quantification of $\mathrm{I}-\kappa \mathrm{B} \alpha, \mathrm{p} 38$, and phospho-p38 cells in the hippocampus CAI (a, d, g), CA3 (b, e, h), and DG (c, f, i) subregions of exposed rats treated with saline $(n=10)$ and exposed rats treated with PDTC $(n=10)$. Administration of PDTC immediately after exposure significantly increased expression of $\mathrm{I}-\kappa \mathrm{B} \alpha, \mathrm{p} 38$, and phospho-p38 in the hippocampal CAI area, CA3, and DG when compared with exposed animals treated with vehicle. All data represent group mean \pm SEM. DG, dentate gyrus; CAI, cornu ammonis I; EBR, extreme behavioral response; MBR, minimal behavioral response; PBR, partial behavioral response; PSS, predator scent stress.

The use of the two NF- $\kappa \mathrm{B}$ inhibitors elicited interesting results. The fact that PDTC not only corrected the NF- $\kappa \mathrm{B} / \mathrm{p} 38$ pathway but also the behavioral response pattern, combined with the fact that high-dose corticosterone not only predictably corrected behavior but also had a similar corrective effect to PDTC on the NF- $\kappa \mathrm{B} / \mathrm{p} 38$ pathway, is pivotal. The implication of these findings is that NF- $\kappa \mathrm{B} / \mathrm{p} 38$ pathway is integrated with steroid receptor signaling (Liberman et al, 2009) and its correlated molecular signaling (kinases and phosphatases) in the context of stress-related disorders. The final outcome of an adaptive stress response will depend on the satisfactory crosstalk between the NF- $\kappa \mathrm{B}$ complex and steroid receptor signaling, whereas abnormal cross-talk or nonregulated NF$\kappa \mathrm{B}$ activation may cause several pathological states.

Taken together, our data led us to the speculation that stress-induced upregulation of NF- $\kappa \mathrm{B}$ levels in the hippocampus may contribute to the imbalance between normally precisely orchestrated physiological and behavioral processes and are thus associated with stress-related disorders. Further studies will be required to examine whether pharmacological inhibition of NF- $\kappa \mathrm{B}$ complex represents an avenue for secondary prevention or treatment of stressrelated clinical disorders.

\section{ACKNOWLEDGEMENTS}

This study was supported by a grant from the National Institute for Psychobiology in Israel, funded by Charles E
Smith Family, the Israel Academy of Science and Humanities (Grant no. 429/03), and by the Ministry of Health (Grant no. 6086) given to HC.

\section{DISCLOSURE}

The authors declare no conflict of interest.

\section{REFERENCES}

Aljada A, Ghanim H, Assian E, Mohanty P, Hamouda W, Garg R et al (1999). Increased IkappaB expression and diminished nuclear NF-kappaB in human mononuclear cells following hydrocortisone injection. J Clin Endocrinol Metab 84: 3386-3389.

Almawi W, Melemedjian O (2002). Negative regulation of nuclear factor-kappaB activation and function by glucocorticoids. $J \mathrm{Mol}$ Endocrinol 28: 69-78.

Auphan N, DiDonato JA, Rosette C, Helmberg A, Karin M (1995). Immunosuppression by glucocorticoids: inhibition of

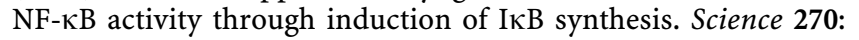
286-290.

Baeuerle P, Baltimore D (1996). NF-B: ten years after. Cell Death Differ 87: 13-20.

Baeuerle PA, Baltimore D (1988). kappa B: a specific inhibitor of the NF-kappa B transcription factor. Science 242: 540-546.

Barger S, Horster D, Furukawa K, Goodman Y, Krieglestein J, Mattson M (1995). Tumor necrosis factors alpha and beta protect neurons against amyloid-peptide toxicity: evidence for involvement of a B-binding factor and attenuation of peroxide and Ca2+ accumulation. Proc Natl Acad Sci USA 92: 9328-9332. 
Beck IM, Vanden Berghe W, Vermeulen L, Bougarne N, Vander Cruyssen B, Haegeman G et al (2008). Altered subcellular distribution of MSK1 induced by glucocorticoids contributes to NF-kappaB inhibition. EMBO J 27: 1682-1693.

Ben-Neriah Y (2002). Regulatory functions of ubiquitination in the immune system. Nat Immunol 3: 20-26.

Bhakar AL, Tannis LL, Zeindler C, Russo MP, Jobin C, Park DS et al (2002). Constitutive nuclear factor-kappa B activity is required for central neuron survival. J Neurosci 22: 8466-8475.

Bierhaus A, Wolf J, Andrassy M, Rohleder N, Humpert PM, Petrov D et al (2003). A mechanism converting psychosocial stress into mononuclear cell activation. Proc Natl Acad Sci USA 1004: $1920-1925$.

Calleros L, Lasa M, Toro MJ, Chiloeches A (2006). Low cell cholesterol levels increase NFkappaB activity through a p38 MAPK-dependent mechanism. Cell Signal 18: 2292-2301.

Carter AB, Knudtson KL, Monick MM, Hunninghake GW (1999). The p38 mitogen-activated protein kinase is required for NF- $\kappa \mathrm{B}-$ dependent gene expression. The role of TATA-binding protein (TBP). J Biol Chem 274: 30858-30863.

Chen Z, Gardi J, Kushikata T, Fang J, Krueger JM (1999). Nuclear factor-kappa B-like activity increases in murine cerebral cortex after sleep deprivation. Am J Physiol 276: R1812-R1818.

Clemens J, Stephenson D, Smalstig E, Dixon E, Little S (1997). Global ischemia activates nuclear factor-B in forebrain neurons of rats. Stroke 28: 1073-1080.

Cohen H, Matar M, Buskila D, Kaplan Z, Zohar J (2008a). Early post-stressor intervention with high dose corticosterone attenuates post traumatic stress response in an animal model of PTSD. Biol Psychiatry 64: 708-717.

Cohen H, Matar MA, Buskila D, Kaplan Z, Zohar J (2008b). Early post-stressor intervention with high dose corticosterone attenuates post traumatic stress response in an animal model of PTSD. Biol Psychiatry 15: 708-717.

Cohen H, Zohar J (2004). Animal models of post traumatic stress disorder: the use of cut off behavioral criteria. Ann NY Acad Sci 1032: $167-178$.

Cohen H, Zohar J, Gidron Y, Matar MA, Belkind D, Loewenthal U et al (2006). Blunted HPA axis response to stress influences susceptibility to posttraumatic stress response in rats. Biol Psychiatry 59: 1208-1218.

Cohen H, Zohar J, Matar M (2003). The relevance of differential response to trauma in an animal model of post-traumatic stress disorder. Biol Psychiatry 15: 463-473.

Cohen H, Zohar J, Matar MA, Kaplan Z, Geva AB (2005). Unsupervised fuzzy clustering analysis supports behavioral cutoff criteria in an animal model of posttraumatic stress disorder. Biol Psychiatry 58: 640-650.

Cohen H, Zohar J, Matar MA, Zeev K, Loewenthal U, Richter-Levin G (2004). Setting apart the affected: the use of behavioral criteria in animal models of post traumatic stress disorder. Neuropsychopharmacology 29: 1962-1970.

Cuzzocrea S, Chatterjee PK, Mazzon E, Dugo L, Serraino I, Britti D et al (2002). Pyrrolidine dithiocarbamate attenuates the development of acute and chronic inflammation. Br J Pharmacol 135: 496-510.

De Bosscher K, Haegeman G (2009). Minireview: latest perspectives on antiinflammatory actions of glucocorticoids. $\mathrm{Mol}$ Endocrinol 23: 281-291.

De Bosscher K, Vanden Berghe W, Haegeman G (2000). Mechanisms of anti-inflammatory action and of immunosuppression by glucocorticoids: negative interference of activated glucocorticoid receptor with transcription factors. J Neuroimmunol 109: 16-22.

Denk A, Wirth T, Baumann B (2000). NF-kappaB transcription factors: critical regulators of hematopoiesis and neuronal survival. Cytokine Growth Factor Rev 11: 303-320.
Finco TS, Baldwin AS (1995). Mechanistic aspects of NF-kappa B regulation: the emerging role of phosphorylation and proteolysis. Immunity 3: 263-272.

Freudenthal R, Boccia MM, Acosta GB, Blake MG, Merlo E, Baratti $\mathrm{CM}$ et al (2005). NF-kappa B transcription factor is required for inhibitory avoidance long-term memory in mice. Eur J Neurosci 21: 2845-2852.

Fridmacher V, Kaltschmidt B, Goudeau B, Ndiaye D, Rossi FM, Pfeiffer J et al (2003). Forebrain-specific neuronal inhibition of nuclear factor-kappaB activity leads to loss of neuroprotection. J Neurosci 23: 9403-9408.

Grilli M, Pizzi M, Memo M, Spano P (1996). Neuroprotection by aspirin and sodium salicylate through blockade of NF-B activation. Science 274: 1383-1385.

Guo Q, Robinson N, Mattson MP (1998). Secreted beta-amyloid precursor protein counteracts the proapoptotic action of mutant presenilin-1 by activation of NF-kappaB and stabilization of calcium homeostasis. J Biol Chem 273: 12341-12351.

Harvey BH, Bothma T, Nel A, Wegener G, Stein DJ (2005). Involvement of the NMDA receptor, NO-cyclic GMP and nuclear factor K-beta in an animal model of repeated trauma. Hum Psychopharmacol 20: 367-373.

Hayakawa M, Miyashita H, Sakamoto I, Kitagawa M, Tanaka H, Yasuda $\mathrm{H}$ et al (2003). Evidence that reactive oxygen species do not mediate NF-kappaB activation. EMBO J 22: 3356-3366.

Kaltschmidt B, Widera D, Kaltschmidt C (2005). Signaling via NF-kappaB in the nervous system. Biochim Biophys Acta 1745: 287-299.

Kaltschmidt C, Kaltschmidt B, Baeuerle P (1995). Stimulation of ionotropic glutamate receptors activates transcription factor NF-B in primary neurons. Proc Natl Acad Sci USA 92: 9618-9622.

Karunakaran S, Ravindranath V (2009). Activation of p38 MAPK in the substantia nigra leads to nuclear translocation of NF-kappaB in MPTP-treated mice: implication in Parkinson's disease. J Neurochem 109: 1791-1799.

Kassed CA, Herkenham M (2004). NF-kappaB p50-deficient mice show reduced anxiety-like behaviors in tests of exploratory drive and anxiety. Behav Brain Res 154: 577-584.

King EM, Holden NS, Gong W, Rider CF, Newton R (2009). Inhibition of NF-kappaB-dependent transcription by MKP-1: transcriptional repression by glucocorticoids occurring via p38 MAPK. J Biol Chem 284: 26803-26815.

Koo JW, Russo SJ, Ferguson D, Nestler EJ, Duman RS (2010). Nuclear factor-kappaB is a critical mediator of stress-impaired neurogenesis and depressive behavior. Proc Natl Acad Sci USA 107: 2669-2674.

Kozlovsky N, Matar MA, Kaplan Z, Zohar J, Cohen H (2009). A distinct pattern of intracellular glucocorticoid-related responses is associated with extreme behavioral response to stress in an animal model of post-traumatic stress disorder. Eur Neuropsychopharmacol 19: 759-771.

Kubera M, Obuchowicz E, Goehler L, Brzeszcz J, Maes M (2011). In animal models, psychosocial stress-induced (neuro)inflammation, apoptosis and reduced neurogenesis are associated to the onset of depression. Prog Neuropsychopharmacol Biol Psychiatry 35: 744-759.

Li H, Li X, Jia N, Cai Q, Bai Z, Chen R et al (2008). NF-kappaB regulates prenatal stress-induced cognitive impairment in offspring rats. Behav Neurosci 122: 331-339.

Li Q, Verma IM (2002). NF-kappaB regulation in the immune system. Nat Rev Immunol 2: 725-734.

Liberman AC, Druker J, Garcia FA, Holsboer F, Arzt E (2009). Intracellular molecular signaling. Basis for specificity to glucocorticoid anti-inflammatory actions. Ann NY Acad Sci 1153: 6-13.

Liu SF, Ye X, Malik AB (1999). Inhibition of NF-kappaB activation by pyrrolidine dithiocarbamate prevents in vivo expression of proinflammatory genes. Circulation 100: 1330-1337. 
Madrigal J, Moro M, Lizasoain I, Lorenzo P, Castrillo A, Bosca L et al (2001). Inducible nitric oxide synthase expression in brain cortex after acute restraint stress is regulated by nuclear factor kappaB-mediated mechanisms. J Neurochem 76: 532-538.

Maggirwar S, Sarmiere P, Dewhurst S, Freeman R (1998). Nerve growth factor-dependent activation of NF-B contributes to survival of sympathetic neurons. J Neurosci 18: 10356-10365.

Majdalawieh A, Ro HS (2010). Regulation of IkappaBalpha function and NF-kappaB signaling: AEBP1 is a novel proinflammatory mediator in macrophages. Mediators Inflamm 2010: 823821.

Mattson M, Goodman Y, Luo H, Fu W, Furukawa K (1997). Activation of NF-B protects hippocampal neurons against oxidative stress-induced apoptosis: evidence for induction of $\mathrm{Mn}-\mathrm{SOD}$ and suppression of peroxynitrite production and protein tyrosine nitration. J Neurosci Res 49: 681-697.

Mattson MP (2005). NF-kappa B in the survival and plasticity of neurons. Neurochem Res 30: 883-893.

Mattson MP, Meffert MK (2006). Roles for NF-kappa B in nerve cell survival, plasticity, and disease. Cell Death Differ 13: 852-860.

McKay L, Cidlowski J (1999). Molecular control of immune/ inflammatory responses: interactions between nuclear factor- $\mathrm{kB}$ and steroid receptor-signaling pathways. Endocrine Rev 20: 435-459.

Meffert MK, Baltimore D (2005). Physiological functions for brain NF-kappaB. Trends Neurosci 28: 37-43.

Munhoz CD, Lepsch LB, Kawamoto EM, Malta MB, Lima Lde S, Avellar MC et al (2006). Chronic unpredictable stress exacerbates lipopolysaccharide-induced activation of nuclear factor-kappaB in the frontal cortex and hippocampus via glucocorticoid secretion. J Neurosci 26: 3813-3820.

Nurmi A, Goldsteins G, Narvainen J, Pihlaja R, Ahtoniemi T, Grohn $\mathrm{O}$ et al (2006). Antioxidant pyrrolidine dithiocarbamate activates Akt-GSK signaling and is neuroprotective in neonatal hypoxia-ischemia. Free Radic Biol Med 40: 1776-1784.

O’Mahony A, Raber J, Montano M, Foehr E, Han V, Lu SM et al (2006). NF-kappa B/Rel regulates inhibitory and excitatory neuronal function and synaptic plasticity. Mol Cell Biol 26: 7283-7298.

Pace TW, Mletzko TC, Alagbe O, Musselman DL, Nemeroff CB, Miller AH et al (2006). Increased stress-induced inflammatory responses in male patients with major depression and increased early life stress. Am J Psychiatry 163: 1630-1633.

Paxinos G, Watson C (2005). The Rat Brain in Stereotaxic Coordinates, 5th edn. Elsevier Academic Press: Burlington, MA.

Pfeilschifter W, Czech B, Hoffmann BP, Sujak M, Kahles T, Steinmetz $\mathrm{H}$ et al (2010). Pyrrolidine dithiocarbamate activates p38 MAPK and protects brain endothelial cells from apoptosis: a mechanism for the protective effect in stroke? Neurochem Res 35: 1391-1401.

Quan N, He L, Lai W, Shen T, Herkenham M (2000). Induction of IB mRNA expression in the brain by glucocorticoids: a negative feedback mechanism for immune-to-brain signaling. J Neurosci 20: 6473-6477.
Richlin V, Arevalo J, Zack J, Cole S (2004). Stress-induced enhancement of NF-B DNA-binding in the peripheral blood leukocyte pool: effects of lymphocyte redistribution. Brain Behav Immun 18: 231-237.

Scheinman RI, Cogswell PC, Lofquist AK, Baldwin S (1995). Role of transcriptional activation of $\mathrm{I} \kappa \mathrm{B} \alpha$ in mediation of immunosuppression by glucocorticoids. Science 270: 283-286.

Schmitz ML, Bacher S, Kracht M (2001). I kappa B-independent control of NF-kappa B activity by modulatory phosphorylations. Trends Biochem Sci 26: 186-190.

Schreck R, Baeuerle P (1994). Assessing oxygen radicals as mediators in activation of inducible eukaryotic transcription factor NF-kappa B. Methods Enzymol 234: 151-163.

Schreck R, Meier B, Männel DN, Dröge W, Baeuerle PA (1992). Dithiocarbamates as potent inhibitors of nuclear factor kappa $B$ activation in intact cells. J Exp Med 175: 1181-1194.

Soerensen J, Pekcec A, Fuest C, Nickel A, Potschka H (2009). Pyrrolidine dithiocarbamate protects the piriform cortex in the pilocarpine status epilepticus model. Epilepsy Res 87: 177-183.

Spencer RL, Kalman BA, Cotter CS, Deak T (2000). Discrimination between changes in glucocorticoid receptor expression and activation in rat brain using western blot analysis. Brain Res $\mathbf{8 6 8}$ : 275-286.

Szatmary Z, Garabedian MJ, Vilcek J (2004). Inhibition of glucocorticoid receptor-mediated transcriptional activation by p38 mitogen-activated protein (MAP) kinase. J Biol Chem 279: 43708-43715.

Taglialatela G, Robinson R, Perez-Polo J (1997). Inhibition of nuclear factor-B (NF-B) activity induces nerve growth factorresistant apoptosis in PC12 cells. J Neurosci Res 47: 155-162.

Unlap M, Jope R (1997). Dexamethasone attenuates NF-kappa B DNA binding activity without inducing I kappa B levels in rat brain in vivo. Brain Res Mol Brain Res 45: 83-89.

Vanden Berghe W, Plaisance S, Boone E, De Bosscher K, Schmitz ML, Fiers W et al (1998). p38 and extracellular signal-regulated kinase mitogen-activated protein kinase pathways are required for nuclear factor- $\kappa \mathrm{B}$ p 65 transactivation mediated by tumor necrosis factor. J Biol Chem 273: 3285-3290.

Vider J, Laaksonen DE, Kilk A, Atalay M, Lehtmaa J, Zilmer M et al (2001). Physical exercise induces activation of NF-kappaB in human peripheral blood lymphocytes. Antioxid Redox Signal 36: 1131-1137.

Webster JI, Tonelli L, Sternberg EM (2002). Neuroendocrine regulation of immunity. Annu Rev Immunol 20: 125-163.

Yeh SH, Lin CH, Lee CF, Gean PW (2002). A requirement of nuclear factor-kappa B activation in fear-potentiated startle. J Biol Chem 277: 46720-46729.

Yu Z, Zhou D, Bruce-Keller AJ, Kindy MS, Mattson MP (1999). Lack of the p50 subunit of nuclear factor-kappaB increases the vulnerability of hippocampal neurons to excitotoxic injury. J Neurosci 19: 8856-8865.

Ziegler-Heitbrock HW, Sternsdorf T, Liese J, Belohradsky B, Weber C, Wedel A et al (1993). Pyrrolidine dithiocarbamate inhibits NF-kappa B mobilization and TNF production in human monocytes. J Immunol 151: 6986-6993. 